\title{
The Effect of Phonetic Training on the Perception and the Production of L1-Related Difficult Sounds in ESL
}

\author{
Moonjung Jang \\ mj0021@mix.wvu.edu
}

Follow this and additional works at: https://researchrepository.wvu.edu/etd

Part of the English Language and Literature Commons

\section{Recommended Citation}

Jang, Moonjung, "The Effect of Phonetic Training on the Perception and the Production of L1-Related Difficult Sounds in ESL" (2019). Graduate Theses, Dissertations, and Problem Reports. 3793.

https://researchrepository.wvu.edu/etd/3793

This Thesis is protected by copyright and/or related rights. It has been brought to you by the The Research Repository @ WVU with permission from the rights-holder(s). You are free to use this Thesis in any way that is permitted by the copyright and related rights legislation that applies to your use. For other uses you must obtain permission from the rights-holder(s) directly, unless additional rights are indicated by a Creative Commons license in the record and/ or on the work itself. This Thesis has been accepted for inclusion in WVU Graduate Theses, Dissertations, and Problem Reports collection by an authorized administrator of The Research Repository @ WVU. For more information, please contact researchrepository@mail.wvu.edu. 
The Effect of Phonetic Training on the Perception and the Production of L1-Related Difficult Sounds in ESL

Moonjung Jang

Thesis submitted

to the Eberly College of Arts and Sciences

at West Virginia University

in partial fulfillment of the requirements for the degree of

M.A. in

Department of World Languages, Literatures, and Linguistics /TESOL

\section{Xiangying Jiang, Ph.D., Chair}

Susan Braidi, Ph.D.

Sandra Stjepanovic, Ph.D.

Department of World Languages, Literatures, and Linguistics

\section{Morgantown, West Virginia}

2019

Keywords: phonetic training, ESL pronunciation, Korean ESL learners, L1 influence, metalinguistics, SLA

Copyright 2019 Moonjung Jang 


\begin{abstract}
The Effect of Phonetic Training on the Perception and the Production of L1-Related Difficult Sounds in ESL
\end{abstract}

Moonjung Jang

A considerable amount of research has been conducted on the influence of first languages' phonological features in pronunciation of a second language. While it has been accepted that pronunciation is one of the most significant aspects in the acquisition of a second language, many studies have not considered whether explicit phonetic training in pronunciation would help English as Second language Learners to improve their pronunciation on particular English sounds that can be confused due to L1 influence. The present study will explore whether Korean ESL learners are able to perceive the particular pairs of the different phonetic sounds (i.e., /p/-/f/, /b/-/v/, /s/-/ $/$, and /r/-/l/) and whether giving Korean ESL learners explicit phonetic training in pronunciation would lead to more accurate perception and production on the targets sounds.

A group of twelve Korean ESL learners took a pre/post-test to evaluate the effectiveness of the treatment, an explicit phonetic training. The phonetics class taught the phonological features of the particular pairs of L1 related difficult sounds of English for two hours by emphasizing the characteristics of each sound in terms of place of articulation, manner of articulation, and voicing. The results showed that there is no significant difference between pre-test and post-test. Thus, the explicit phonetic training was not an effective means of improving pronunciation of ESL learners. 
Table of Contents

-Introduction, p.1

-Review of the Literatures, p.7

-Methods, p.31

-Results, p.41

-Discussion, p.44 


\section{Introduction}

Much research has investigated the role of pronunciation in second language acquisition. The role of pronunciation has changed from theory to theory throughout the history of second language acquisition. "Traditional methods such as Grammar-Translation or the Reading-Based Approach neglected pronunciation teaching completely and considered it irrelevant to language teaching" (Atli \& Bergil, 2012, p.3665). However, other methods such as the Oral Approach or Audiolingualism introduced a new perspective on pronunciation teaching. These methods treated pronunciation teaching as a more fundamental aspect in second language acquisition. 'from 1940's to 1960's, pronunciation teaching was of primary importance in the English Language Teaching Curriculum” (Atli \& Bergil, 2012, p.3665). Even though teaching pronunciation was considered to be necessary and essential, the effectiveness of pronunciation instruction was questioned and challenged; "whether pronunciation should (can) be taught, and if so, what should be taught and how, and whether and how research in second language phonology can inform classroom practices" (Morley, 1991). The complicated issue of whether pronunciation is able to be taught effectively led English as a second language teachers to reduce their attention on teaching pronunciation (Morley, 1991, p.481). By instructional time and attention on pronunciation being reduced, ESL learners do not get many opportunities to work on their pronunciation in a separate or an individual phonetics class or phonetics training despite the importance of pronunciation in second language acquisition. However, there is a clear need of ESL learners for their L2 pronunciation improvement because ESL learners feel that there are communication breakdowns due to their pronunciation of second language (Derwing \& Rossiter, 2002). Derwing and Rossiter (2002) conducted research where the participants were asked how they would react to communication breakdowns in conversation. These participants employed many different strategies such as repetition, paraphrasing, volume, writing or spelling out, 
slowing the speed, or more clearly speaking when they faced the communication breakdowns. More than half of the participants, 55 out of 100, felt that pronunciation was a contributing factor to their communication breakdowns, while there were 39 participants who were not even able to identify and specify their pronunciation problems. Ninety percent of the participants were willing to take a pronunciation course if it was available (Derwing \& Rossiter, 2002). It shows that ESL learners see pronunciation as one of the salient factors when learning English as a second language, and they are willing to work toward improvements on pronunciation.

With pronunciation being considered as an important aspect in second language acquisition, there are multiple factors that influence pronunciation of a second language such as the learners' age or first language. The time when a second language learner starts to learn a second language affects the degree of foreign accent. The foreign accent increases greatly after the age of 15 , and if the learning begins by the age of 6 , an L2 can be spoken without foreign accent (as cited in Flege, Frieda \& Nozawa, 1997). Particularly, the role of the L1 in second language acquisition has been extensively discussed for many decades; however, the significance of L1 transfer to the L2 was not acknowledged at first in second language acquisition (as cited in Grami \& Alzughaibi, 2012). Behaviorism as a theory of learning suggested that second language acquisition equals acquiring a new set of habits. It provided the idea that the mother tongue was very important because the mother tongue was considered the major cause of failures in second language learning (as cited in Grami \& Alzughaibi, 2012). The importance of L1's influence on English as a second language has varied from theory to theory; however, it is recently well accepted that the influence of the L1 exists in second language acquisition. It does not mean that a whole process of learning a second language is controlled or determined by the L1 of a second language learner. Rather, it is clear that L1 transfer or L1 influence on a second language acquisition is very selective, 
which means some parts of an L1 might transfer to a second language acquisition while others might not (Mitchell, Myles \& Marsden, 2013). Pronunciation is the domain where a L1 influences a second language acquisition. It has been accepted that second language learners would perceive the L2 sounds based on their L1, concentrating more on the phonetic contrasts between the L1 and the L2 (Han, Hwang \& Choi, 2011). Each language has different phonetic features, and they affect a second language pronunciation when a second language learner from a particular language tries to learn a second language. Due to the distinct features of many different first languages, second language learners with different language backgrounds can display distinct pronunciation problems when they learn the same second language. Avery \& Ehrlich (2000) introduced possible pronunciation problems of selected language groups such as Italian and Arabic when they learn English as a second language. For example, Arabic ESL learners might have difficulty producing a /p/ sound because Arabic language does not have the /p/ sound. This lack of the sound in their native language could cause Arabic ESL learners to have a pronunciation problem; they may substitute $/ \mathrm{b} /$ for $/ \mathrm{p} /$. Besides the nonexistence of a sound in a first language, a different way of producing a sound may cause a pronunciation problem. For example, English $/ \mathrm{r} /$ sound is the retroflex which means that "it is produced with the tip of the tongue slightly curled back in the mouth" (Avery \& Ehrlich, 2000, p. 23). However, Arabic ESL learners may trill the /r/ sound in a way that they do with their first language, which causes inaccurate English pronunciation of the sound, $/ \mathrm{r} /$.

As Arabic ESL learners and other ESL learners of different first language groups, Korean ESL learners also have pronunciation problems influenced by their first language, and it "can be quite severe because of the radical differences between the sound system of Korean and English" (Avery \& Ehrlich, 2000, p.138). "For example, pertaining to the present study, typical influences of Korean phonology on the production of English include 
adaptations of consonant clusters, strategies for mapping Korean's series of three stop consonants to English's two, mapping English dental and labiodental fricatives to Korean stops, vowel epenthesis, and mapping English's two liquid consonants to allophones of Korean's one" (as cited in Kim \& Billington, 2018, p. 141). Han, Hwang, and Choi (2011) examined a study where native Korean speakers participated to identify whether they were able to produce reduced vowels knowns as a schwa or barred-i, which does not exist in Korean. Twenty nine native Korean speakers participated in the study, and they were divided into two groups depending on their residence length in English speaking countries: fourteen participants were grouped as the RA group meaning "residence abroad more than a year," and fifteen participants were grouped as the No RA group meaning "no residence abroad." The study revealed that the longer the native Korean speakers lived in English speaking countries, the better they were able to produce the target sounds to the ones of English native speakers. However, even the participants who had lived in English speaking countries were not able to produce as exactly as English speakers do due to their L1 influence.

Much research as introduced above has demonstrated that pronunciation is a salient factor in a second language acquisition, and the phonetic features of the L1 do have effects on pronunciation of ESL learners (Grami \& Alzughaibi, 2012). However, despite the importance of pronunciation in a second language acquisition and the different L2 pronunciation problems caused by the learners' L1, there is still little research about whether second language learners can perceive L1-related difficult sounds of the L2 and improve their pronunciation on them through phonetics training.

The study aimed to examine whether Korean ESL learners can perceive their firstlanguage-related difficult English sounds and improve their English pronunciation on them through a phonetics class. Among many first-language-related difficult English sounds, four 
pairs were selected from Teaching American English Pronunciation by Avery \& Ehrlich, (2000); /b/-/v/, /p/-/f/, /s/-/ /, and /r/-/l/. The pair of /b/-/v/ and the pair of /p/-/f/ were selected because the English sound /f/ and the English sound /v/ do not exist in Korean, and Korean ESL learners "tend to substitute /p/ and /b/, respectively" (Avery \& Enrlich, 2000). The pair of $/ \mathrm{s} /-/ \int /$ and the pair of $/ \mathrm{r} /-/ 1 /$ were selected because/s/-/ $/$ and $/ \mathrm{r} /-/ 1 /$ are different sounds in English, but they are allophones in Korean. /s/-/ / are allophones of a phoneme, $\curlywedge$. The sound ' $\mathrm{s}$ ' in Korean is pronounced "as either / $/$ / or as aspirated /s/" (Avery \& Enrlich, 2000). The other pair /r/-/1/ are also allophones of a phoneme, ᄅ, in Korean, and this causes Korean ESL learners to "substitute the sounds /1/ for the sounds / $\mathrm{r}$ / in initial position" (Avery \& Enrlich, 2000).

This study a provides literature review regarding related topics; an L1's influence on L2 English pronunciation, ESL learners' perceptions of their own English pronunciation and different English accents to identify their attitudes toward English pronunciation as a second language, English pronunciation of Korean ESL learners, and the effectiveness of phonetic training. These studies introduced preceding and current issues in the second language acquisition field; however, the researcher found a gap among these studies, raised a few research questions regarding the effectiveness of phonetic training on L1-related difficult L2 sounds, and conducted a study to examine the questions. Twelve Korean native speakers participated in the study to test whether phonetic training of two hours on the particular four pairs of their L1-related difficult English sounds would help them to improve their pronunciation on the pairs. Two hours of phonetics training took place in two days, and each hour focused on two pairs, /b/-/v/, /p/-/f/, /s/-/s/, and /r/-/1/, respectively. Pre-and post-tests were conducted, and in-class activities were provided to the participants for practice on the 
pairs. The data analyzed showed that there is no significant difference, and the study discussed its weaknesses and implications in the discussion part. 


\section{Review of the Literature}

Numerous studies have been conducted in the second language acquisition field, and different means to find out a best way to teach English to English as a second language learners have been introduced. It includes multiple learning theories from Behaviorism in the 1950s to communicative teaching (Grami \& Alzughaibi 2012). This chapter will introduce a few studies focusing on L1 influence on English as a second language, ESL learners' perception on their own English pronunciation and different English accents, English pronunciation of Korean ESL learners, and the effectiveness of phonetic training. It will explicitly analyze the findings of each article with a goal of understanding how these findings can be put together to see the relation between ESL learner's pronunciation and the effectiveness of phonetic training.

\section{The Influence of L1 Phonological Features on L2 English Pronunciation}

There have been numerous articles exploring the effects of L1 phonological features on ESL learners' acquisition of English. Some articles have provided specific examples of how particular L1s influence English acquisition. Chan (2011) conducted an experiment to examine the perception of English speech sounds by Cantonese ESL learners in Hong Kong. The participants included forty Hong Kong Cantonese ESL learners composed of 29 females and 11 males with varying ages. All of the participants were English majors in Hong Kong. All of them started to learn English at the age of six or earlier. Twenty six participants had some kind of phonetics training before, while 14 participants had not received any type of phonetics training. The participants were given three listening tasks: a categorical discrimination task and two L2 minimal pair identification tasks individually. For the first task, the participants listened to seventy-two trios of phones, with two instances of one phoneme in different positions and one instance of another phoneme in the remaining 
position for each trio. For the second task, the participants listened to eighty-five English minimal pairs and chose what they think they heard from the response sheet. For the last task, the participants listened to a word in a sentence and had to pick a picture representing the word from two options. From the data collected, Chan (2011) had hypothesized that if ESL learners perceive some particular sounds more easily than others, they would produce them better because better perception was expected to lead to a better production. However, the findings did not exhibit the relationship between production and perception. The study discovered that ESL learners perceived particular sounds that exist in their first language better than the others that are nonexistent or sound differently in their first language. The study has revealed that ESL learners perceive sounds through their first language sound system although the perception of the sounds does not influence production of the sounds.

The effect of phonological features of the L1 on pronunciation of L2 English was confirmed by the research of Leahy (1980). One hundred twenty four ESL learners participated in the research. There were four subgroups based on their first languages: 62 Spanish, 36 Farsi, 14 Arabic, and 12 Japanese ESL learners. Oral interviews were carried out using the Sound Properties Production Test to determine what the missing phonemes of English are in each group of ESL learners. During the interviews, the subjects were asked to read a set of cards of 89 words chosen to elicit a specific target sound in word initial, medial or final environment. The results showed that most of the ESL learners had errors with the dimensions of voicing and continuance although each subgroup exhibited different problems. Leahy (1980) pointed out that these errors should be dealt with in conjunction with the words surround the errors. ESL learners must pay attention to not only the problematic sounds but also the surrounding sounds to improve their English pronunciation. Leahy (1980) proposed that ESL instructors should be concerned with pronunciation of ESL learners to improve their well-being because living as foreigners in English-speaking countries, they tend to 
concentrate more on how something is said, i.e., the way of saying it, rather than what is actually said, i.e., the content. Helping ESL learners to improve on their L2 pronunciation would protect them from prejudice of being a language minority in an L2 society. The research has shown that each group of ESL learners with a particular first language have different problems because each language has its peculiar sound system through which ESL learners perceive the sounds of English.

The influence of the first language does not only affect perception of L2 English sounds but also production of L2 English in multiple domains such as pronunciation and stress. Hsieh and Venkatagiri (1994) conducted research to investigate whether or not the production of stress and syllable duration at the word level was influenced by differences in proficiency of Chinese ESL learners. The nonnative group included three intermediate and three advanced Chinese international teaching assistant (ITAs). The native group was three male native speakers of American English. The test consisted of nine sentences with different numbers of syllables. The participants were asked to read the sentences. The researchers used all of the nine sentences to investigate pausing, but used only five sentences to investigate syllable duration. The results showed a difference between the productions of the native English speakers and the nonnative speakers. The native English speaker group paused only in the long sentences with two clauses; however, all of the nonnative speakers regardless of their proficiency paused for both medium and long sentences although the high proficiency students were closer to the natives in terms of the pause rates. The result indicated that pausing and syllable duration are influenced by first languages at the early phase of learning although they are learnable. Since the research has a small number of participants, and the research was conducted only on an oral-sentence reading task, they asked that future research replicate the study with a larger sample size and with different types of speech such as spontaneous speech. The study has demonstrated that although pausing and syllable duration 
are learnable, not only low proficiency ESL learners but even high proficiency ESL learners are still influenced by their first language in production of pausing and syllable duration.

Saha and Das Mandal (2016) conducted an experiment to explore how the different system of lexical stress in Bengali affects Bengali ESL learners' on their production of lexical stress in English. Both of the languages are stress-accent languages "where words are assumed to bear stress on, at least, one syllable and pitch accent is assigned to a syllable with primary stress" (p.828); however, Bengali is different from English in terms that stress is predicable, and minimal pairs do not exist in Bengali. Ten (5 male, 5 female) L1 American English speakers and 20 (8 male, 12 female) L1 speakers of Standard Colloquial Bengali participated in the study. The average fluency of the L1 Bengali speakers was level 3.6 and above on a 5-point MOS scale, i.e., Mean Opinion Scale. The L1 Bengali speakers were tested on their English fluency in terms of naturalness, lexical stress, and segmental correctness. The test consisted of seven pairs of disyllabic words consisting of a noun and a verb that had identical spelling forms and differed only in terms of stress placement. The target words were randomly presented to each group of the participants, and the L1 English speakers and the L1 Bengali speakers produced them in the neutral frame sentence 'I said test word this time'. The stressed syllable of each target word was marked in the neutral frame sentence when the target words were given to both groups of the participants. Their productions were recorded. The data were analyzed based on four standards; duration, intensity, fundamental frequency, and vowel quality. The result of duration analysis showed that L1 English speakers produced more differences between duration of stressed and unstressed vowel than L1 Bengali speakers, while the result of intensity analysis revealed that the average and peak intensity of stressed vowel was higher than its unstressed counterpart for both groups. The result of fundamental frequency exhibited that when vowels were stressed, their fundamental frequency was also increased. The result of vowel quality 
displayed that vowel reduction which is one of the important features of American English was not found in vowel productions of native Bengali speakers. The total results indicated that the lexical stress in English by L1 Bengali speakers differed from the one of their L1 native English speaker counterparts in terms of reducing vowels in unstressed syllables because stress does not affect vowel quality in Bengali. Saha and Das Mandal (2016) regarded the results as an implication of L1 transfer because L1 Bengali speakers mostly failed to produce correct production of reduced vowel in English unstressed syllables and full vowel in English stressed syllables due to the lack of a vowel reduction feature in Bengali.

These studies above have demonstrated that the influence that the L1 has on the acquisition of English can be tremendous. Chan (2011) and Leahy (1980) showed that the ESL learners had L2 English pronunciation problems related to their first languages, and although some L2 English sounds were easier for the ESL learners to perceive, easier perception was not related to better production. Hsieh and Venkatagiri (1994) and Saha and Das Mandal (2016) extended the range of L1 influences beyond pronunciation. They showed that the L1 of ESL learners also affected other L2 components such as stress, pausing, and intonation. ESL learners transfer their L1 features into the L2; however, it is unpredictable, i.e., where L1 transfer would happen in an L2 differs from student to student. Moreover, most of the ESL learners are not aware of the influence of the L1. Thus, helping ESL learners to beware of the influence of the L1, and paying attention to the problems caused by the L1 could be very advantageous.

\section{ESL Learners' Perceptions on their Pronunciation of English and English Accents}

Much research has investigated how ESL learners understand their pronunciation of English and what kind of pronunciation problems and needs ESL learners have. Derwing (2003) conducted interviews concerning the ESL learners' perceptions of their pronunciation 
and accents. Interviews were administered to determine whether the ESL learners perceive their pronunciation problems or not, and what kinds of pronunciation problems they think they have, considering whether the visible language minority status of the ESL learners makes a difference in acceptance from others in an L2 society. A hundred adult immigrants studying in an ESL program (64 females, 36 males) from 19 different language backgrounds participated in the study. Fifty-eight percentage of the participants were visible minorities. The participants were given a questionnaire with a seven-point scale. There were also openended questions during the interviews. The participants were asked to answer the questions during the interview time period of 50 to 90 minutes, and the researchers were recording the conversation while writing down the responses in the interview sheet. The analysis of the interviews showed that forty three percent of the participants felt that their communication breakdowns in L2 English happened due to language problems in general, and forty two percent of the participants thought that communication breakdowns in L2 English were caused by pronunciation problems. Moreover, more than 50 interviewees reported that they had pronunciation problems; however, they could not specify what their pronunciation problems were. Even a small number of ESL learners who were able to point out their pronunciation problems focused on individual segments instead of prosodic factors. Derwing (2003) analyzed the participants' perceptions on their pronunciation problems and listeners' attitudes towards their foreign accents. She concluded that a lot of ESL learners thought that they had pronunciation problems that caused communication breakdowns, and the ESL learners felt discriminated against sometimes due to their foreign accents. Derwing (2003) suggested that ESL learners should be able to have an opportunity to improve their pronunciation with appropriate help because they would like to work on their pronunciation to be more intelligible, but it is hard for them to do so by themselves. 
Derwing and Rossiter (2002) conducted an experiment to investigate ESL learners' perception of their pronunciation problems and problem-solving strategies by testing whether there were mismatches among the ESL learners' perception of their pronunciation needs, the instruction that they received, and the natural inclinations to deal with communication breakdown. A hundred participants (36 males, 64 females) with varying ages and L1 backgrounds joined the experiment. Their proficiency varied from low to high intermediate based on the placement test by a local college. There were four large subgroups: twenty eight Polish L1 speakers, eighteen Spanish L1 speakers, fourteen Cantonese L1 speakers, and thirteen Japanese L1 speakers. Every participant had a one-to-one interview for a half hour. They were asked to respond to the questionnaire on a seven point scale about communication difficulties with a few open-ended questions. More than one third of the participants said they experienced a communication breakdown and were asked by others to repeat themselves again. They were also asked to determine if they think the communication difficulties result from either language problems or pronunciation problems or both. Fifty-five participants realized that pronunciation is the main cause of communication breakdown. Fifty-six percent of the participants preferred paraphrasing as their best and favorable strategies across the subgroups when they were requested to repeat themselves although each subgroup showed a different preference among other strategies such as self-repetition and writing or spelling. The analysis indicated that pronunciation instruction in pronunciation class with emphasis on segmentals was not matched with ESL learners' attitudes toward pronunciation problems; the ESL learners preferred suprasegmentals as their strategies for communication breakdowns. Interestingly, even though ESL learners favored supragsegmentals as their strategies, they were more likely to be concerned with segmentals such as minimal pairs which do not hinder intelligibility in context. Derwing and Rossiter (2002) urged the instructors to encourage students to concentrate more on suprasegmentals which plays a more salient role in context. 
Cenoz and Lecumbeni (1999) designed an experiment to investigate the awareness, beliefs, and attitudes of ESL learners of Basque and Spanish regarding English pronunciation. Eighty-six participants (17 male, 69 female) were university students who all majored in English. The first language of $61.6 \%$ of the participants was Spanish, whereas $38.4 \%$ had either Basque or Basque and Spanish as their first languages. They were asked to fill in a background questionnaire and answer specific questions about their awareness, beliefs, and attitudes on English pronunciation. The study took place in one of their phonetics classes, and the data they collected were analyzed by the SPSS program. Five variables were considered: awareness of the difficulty of English pronunciation, awareness of importance of English pronunciation, beliefs about factors that influence the acquisition of pronunciation, difficulty of English accents such as British or American English, and attitudes towards English accents. The results showed that the two groups of ESL learners shared the perception of the importance and difficulty of English segmentals and suprasegmentals. They also picked the same factors that are the most influential on their pronunciation, i.e., contact with native speakers and ear training. The attitudes on different accents such as British, American, and Irish were similar in the two groups. Both of them preferred British and Irish English over American English, showing that the familiarity with a particular accent affects learners' perception and attitudes at a certain accent. Thus, the results revealed that all of the participants were aware of difficulty of English pronunciation with the possible reason that it is because of the difference between the English phonetic system and the Basque or Spanish systems at segmental and suprasegemental levels. Cenoz and Lecumbeni (1999) recommended that ESL teachers access their students' needs and help them to build up healthy beliefs about English pronunciation so that negative, wrong beliefs cannot affect the acquisition process of ESL learners. 
Kang (2015) administered a study to explore how ESL and EFL learners from different regions of the world perceive and evaluate their pronunciation and what attitudes they have towards their instructors' pronunciation. Kang (2015) constructed the concept of the three concentric circles referring to Kachru (1992) to indicate the status of English as either native, official, or foreign language. The inner circle (IC) refers to the countries where English is used as a native language, whereas the outer circle (OC) refers to the countries where English is spoken as the official second language. The expanding circle (EC) refers to the countries where English is learned as a foreign language. Six hundred and seventeen ESL and EFL students were invited to participate in the research, but only 117 students ended up participating in it, of which 25 participants were from the U.S. and New Zealand, 21 participants from South Africa and Pakistan, and 71 from South Korea and Japan. The participants were asked to answer the questionnaires with scalar judgements on a 6-point scale $(1=$ strongly agree, $6=$ strongly disagree, and NA=not applicable $)$ and 10 open-ended questions through online interview tools. The results explicitly showed that all three groups of the participants somewhat agreed that learning English pronunciation is confusing because of its varieties such as British and American English although ESL students from each circle displayed different pronunciation needs and attitudes towards the pronunciation of their instructors. The researcher made suggestions for ESL teachers to diagnose and analyze the different needs of their ESL learners and to provide as many adjusted personal solutions as they can.

Scales, Wennerstrom, Richard, and Wu (2006) conducted an experiment to find a view and attitudes of ESL learners in English speaking countries on their L2 English accents and other English accents. The researchers were curious to find out what English accents ESL learners in the U.S. prefer the most and would like to emulate as their goal for L2 English pronunciation, and whether they have an ability to distinguish the various English accents 
correctly. Thirty-seven ESL learners participated in the study ranging from intermediate to advanced with different language backgrounds most of which were from Asia. Ten American undergraduate students who were native English speakers also participated in the study. Both of the groups were given a short listening read by four speakers with different accents of British English, American English, Chinese English, and Mexican English. When ESL learners were asked to identify the origin of the four speakers, they had difficulties distinguishing among them, whereas American undergraduates were more successful in identifying the American and Mexican accents. Scales, et al. (2006) thought that this result possibly derived from the participants' familiarity with a particular accent; the accuracy rate of identifying Chinese English was relatively high among Chinese ESL learners. Nine out of eleven Chinese ESL learners were able to identify Chinese English as Chinese English or Taiwanese English or other Asian English. American undergraduate students had a relatively higher accuracy rate of identifying American English and Mexican English than other accents because of the familiarity with these two particular English. With the given results, there was a discrepancy between the goal of the ESL learners and their ability to distinguish different English accents; the majority (62\%) of the ESL learners preferred to sound like a native speaker as their L2 English pronunciation goal instead of being intelligible which was favored by thirty-eight percent of the ESL learners, but " $73 \%$ and $62 \%$ rated the American and British speakers, respectively, as nonnative, and $8 \%$ and $24 \%$ rated the Chinese and Mexican speakers, respectively, as native.” (p.725). Scales, et al. (2006) concluded that even though the ESL learners had a particular English accent that they desired to internalize, they were not able to identify the accent. They suggested that L2 English pronunciation should be taught in a way that ESL learners would be able to "hear, analyze, and compare key features among a variety of accents" to meet the needs of ESL learners and to make them versatile in many communication contexts (p.735). 
The studies above have shown that ESL learners are aware of the significance of pronunciation in terms of communicative purpose. They are willing to improve their pronunciation thinking that having more comprehensible and clearer pronunciation would enhance their ability to communicate through English. However, only a few ESL learners could diagnose and describe their pronunciation problems. They recognize that they have some pronunciation problems, but they cannot identify what the problems are (Derwing, 2003; Derwing \& Rossiter, 2002). In addition, ESL learners showed that they favored a particular accent over another one; however, it was not easy for them to identify different English accents even including a particular accent that they would like to emulate as their goal for L2 English (Kang, 2015; Scales, et al., 2016). It weakens the chance for ESL learners to communicate with people of different accents due to the inability of interlocutors to understand their accented English. Thus, helping ESL learners to identify their pronunciation problems and to be able to deal with multiple English accents would be beneficial to ESL learners.

\section{English Pronunciation of Korean ESL Learners}

Very little research has been conducted on specific L1-related traits of Korean ESL learners. Han, Hwang, and Choi (2011) carried out a study to examine whether residence in English speaking countries would affect their production of reduced vowels known as a schwa or barred-i because reduced vowels do not exist in the Korean language. Twenty-nine native Korean speakers participated in the research. The participants were divided into two groups: fourteen in the RA group meaning 'residence abroad more than a year,' and fifteen in the No RA group meaning "no residence abroad." There was one more group of participants who were native English speakers as controls. All of the native speaking participants were English teachers in Seoul, Korea. Three types of test words were presented to the 
participants. They differed with respect to the position of a reduced vowel: word-initial, word-internal, and word-final positions. Each type of the test words was 12 tokens, consisting of two syllables, of which one syllable was reduced. The test words differed in terms of word types such as mono-morphemic words or bimorphemic words according to the position where stressed vowel can occur: word-initial position being mono-morphemic words (e.g., assist), word-internal position being bimorphemic words (e.g., roses), and word-final position ending with an unstressed vowel with the orthographic letter -a (e.g., Rosa). The full vowels in American English were offered to the participants so that they could be used as reference. Ten additional items of fillers were also provided. All of the words were given in the frame sentence of "I said this word this time". Each of the participants received a list of test words and were asked to review the words to make sure whether there was a word that they had not known before. If there was an unknown word, the experimenter pronounced the word one time so that the participant could know how to pronounce the word. Once all participants knew all of the words, they started recording the test words. Their productions were analyzed on the duration ratio of the reduced vowels to the full vowels and the formant value. The mean duration ratio of reduced vowels to full vowels showed that both English natives and Korean natives produced the reduced vowels as shorter vowels than those of the full vowels in words such as in the assist and roses type words, and less clearly in words of the Rosa type. The difference between English native groups and both of the Korean groups was that English native speakers tended to exhibit smaller difference in duration ratio among the word types than Korean native speakers. The difference between Korean groups was that No RA group showed larger difference in duration ratio among the word types than RA group. The three groups also displayed a difference in either formant frequency $1(\mathrm{~F} 1)$ or formant frequency 2 (F2) values of reduced vowels. The RA group was more similar to the English native group. Thus, the results showed that it was not clear whether L2 learners were able to 
produce certain phonetic contrasts in the L2 which do not exist in L1 in a way that native speakers do although L2 learners who have an experience living in countries where the target language was spoken produced more similar phonetic contrasts than those L2 learners who have never lived abroad.

A study on the attitude of Korean ESL learners towards different accents in English was conducted by Yoo (2012). In the early 1990s, English was chosen as a regular subject of the public and private school curriculum in Korea. Historically and traditionally, East Asian countries including Korea have focused more on grammar, reading, and writing than speaking and communicative ability. However, with time by, the significance of speaking and communicative ability has gotten more attention which raises a question concerning the attitudes Korean ESL learners have towards different accents in English because "it is clear the English now has more non-native speakers than native ones" (as cited in Yoo, 2012). Ninety-two university students who were not majoring in English participated in the research. Their English fluency varied from a complete beginning level to an advanced level. Fiftyeight of the participants were male while thirty-four of the participants were female. The survey was provided to the participants in both English and Korean. Korean was written to help the participants to fully understand the survey, and the survey was anonymous so that the participants could be truthful on their answers. The survey was divided into two sections; one was four listening activities, with each followed by five questions. The participants had to listen to four short 30 -second recordings with different accents such as Chinese and Swedish. Yoo (2012) picked difficult accents to identify the ability of the participants to describe the different accents and whether preconceived ideas would influence their attitudes towards accents. Therefore, the participants were asked to identify where they think the speaker came from based on the given recordings. The other part of the survey was openended questions such as "what is your general opinion of the people from the country?" The 
participants were asked to present their opinions on the open-ended questions. In Section One where the participants listened to the different accents and guessed where the speakers came from, the speakers were from Malaysia, China, South Africa, and Sweden. The results revealed that some Korean ESL learners regarded a non-native accent such as a Malaysian accent as a "western" accent even though the speaker had a clear non-native accent. Yoo (2012) assumed that this result possibly came from the participants' inability to differentiate different English accents because despite a clear non-native accent of the speakers, some Korean ESL learners identified the Malaysian accent as American English and preferred American English, thinking that the Malaysian accent is a standard English. The results of the open-ended questions displayed that eighty-five participants out of ninety-two thought learning accent was important. Seventy-nine participants out of ninety-two answered that the accent of their teacher could affect their ability to learn English properly. Sixty one percentage of the participants preferred the North American accent, and most of the participants thought that it was the most beautiful accent among others, whereas an Asian or South East Asian accent was labelled as an unappealing accent. Yoo (2012) assumed that it would be difficult for Korean ESL learners to differentiate varieties of English accents as it was hard for the researcher to differentiate Korean dialects although she was living in Korea for a number of years. Yoo (2012) explained that Korean ESL learners' preference for North American English may have resulted from not only the accent itself, but also social evaluation on each country and familiarity with each accent; however, she believed that difficulty with understanding a specific accent may have majorly affected the participants' preference. Yoo (2012) concluded that although the reality is moving towards World Englishes meaning that people in many different countries use English with particular accents, Korean ESL learners still favored Inner Circle countries over others due to multiple reasons. 
These studies showed that Korean ESL learners have difficulty pronouncing particular vowel sounds, schwa and barred-i due to the lack of existence of the vowel sounds in Korean (Han, Hwang, and Choi, 2011). It clearly exhibits that Korean ESL learners have difficulty producing particular sounds of English. The studies also displayed that Korean ESL learners have a preference for a particular English accent even though they do not distinguish different English accents even including the desired one (Yoo, 2012). It is necessary for Korean ESL learners to be able to produce intelligible L2 English pronunciation and understand different L2 English accents because English is currently used as an international language in the world. Thus, helping ESL learners to improve on the difficult L2 English sounds and having them to analyze multiple English accents could be beneficial.

\section{The Effectiveness of Phonetic Training}

Table 1 The Summary of the Literature Review Regarding the Phonetic Training

\begin{tabular}{|c|c|c|c|c|}
\hline Study & Sample Size & Target Sounds & $\begin{array}{l}\text { Type of } \\
\text { Treatment }\end{array}$ & $\begin{array}{l}\text { Length of } \\
\text { Treatment }\end{array}$ \\
\hline Kissling (2013) & 95 & $\begin{array}{l}\text { Spanish voiced } \\
\text { stops } / \mathrm{p}, \mathrm{t}, \mathrm{k} / \text {, } \\
\text { approximants } \\
/ \beta, \succsim, \mathrm{\gamma} / \text {, and } \\
\text { rhotics } / \mathrm{r}, \mathrm{c} /\end{array}$ & $\begin{array}{l}\text { Explicit } \\
\text { phonetic } \\
\text { instruction; } \\
\text { corrections on } \\
\text { pronunciation } \\
\text { errors and } \\
\text { focused } \\
\text { instruction on } \\
\text { communication } \\
\text { and fluency }\end{array}$ & $\begin{array}{l}\text { Two weeks of } \\
\text { four } \\
\text { instructional } \\
\text { modules }\end{array}$ \\
\hline $\begin{array}{l}\text { Algethami } \\
\text { (2017) }\end{array}$ & 9 & $\begin{array}{l}\text { English } / \mathrm{p}, \mathrm{v}, \mathrm{t} \int \text {, } \\
\mathrm{I}, \mathrm{y}, \mathrm{e}, \mathfrak{x}, \Lambda, \mathrm{p}, \\
\text { ग: \& 3:/ }\end{array}$ & $\begin{array}{l}\text { Grapheme- } \\
\text { phoneme } \\
\text { correspondence } \\
\text { and an } \\
\text { articulatory } \\
\text { phonetic } \\
\text { description }\end{array}$ & $\begin{array}{l}\text { Eleven weeks of } \\
\text { eleven hours of } \\
\text { pronunciation } \\
\text { instruction }\end{array}$ \\
\hline Wong (2012) & 64 & $\begin{array}{l}\text { English / e/ } \\
\text { and / æ/ }\end{array}$ & $\begin{array}{l}\text { High Variability } \\
\text { Phonetic } \\
\text { Training, which }\end{array}$ & Three weeks \\
\hline
\end{tabular}


Saito (2013)

49

17

Lord (2005)

Saalfeld (2011) 28
English / I/

Spanish

unaspirated

$[\mathrm{p}, \mathrm{t}, \mathrm{k}]$, the

Spanish trilled

[r], diphthongs

within words

and between

words, and the

fricative

allophones $[\beta$,

ð, $\mathrm{\gamma}]$

Spanish words stress

\author{
offers various \\ phonetic \\ contexts \\ produced by \\ multiple \\ speakers. Low \\ Variability \\ Phonetic \\ Training, which \\ offers a single \\ phonetic \\ context \\ produced by a \\ speaker
}

\section{Focused form instruction and \\ explicit \\ instruction that \\ had lectures \\ exaggerate the \\ pronunciation \\ and teach \\ articulatory \\ configuration}

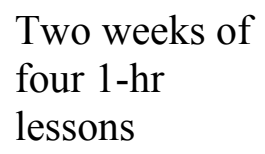

Two weeks of

four $1-\mathrm{hr}$

lessons

Explicit

phonetic

A semester for

training

including

explanations for

articulations,

oral practice,

transcription

practice, etc.

Spanish

phonetics class

Pronunciation A semester
class

A few studies have been trying to test whether explicit phonetic training would be effective in improving pronunciation of second language learners. Kissling (2013) administered a study to test whether there is a different degree of improvement in the 
production of a variety of problematic consonants by English speakers learning Spanish when exposed to explicit pronunciation instruction on the one hand and implicit treatment on the other with similar input, practice, and feedback. Ninety-five participants who were not tested for proficiency participated in this study and were called as first-, second-, and third-year learners. The participants were randomly divided into an experimental group or a control group. The experimental group which is the phonetics instruction group completed four computer-delivered, interactive modules on the target sounds such as voiceless stops $/ \mathrm{p}, \mathrm{t}, \mathrm{k} /$, approximants $/ \beta, \delta, \gamma /$, and rhotics $/ \mathrm{r}, \mathrm{\kappa} /$. The participants in the experimental group received explicit instruction while the control group did not receive any explicit phonetic instruction even though the participants in the control group also completed the self-paced, computerdelivered, interactive online modules. The experimental group received corrections on pronunciation errors on the target sounds, but the group also received more focused instruction on communication and fluency than pronunciation accuracy. The study was designed as pretest, posttest, and delayed posttest. The productions of both groups were analyzed, and it turned out that explicit phonetic instruction did not provide any advantage in productions, either for individual phones or for all phones together. This study claims that the greatest contribution is that the control condition (focused listening with dictation) was as effective for improving pronunciation as the phonetics instruction.

Algethami (2017) conducted research to investigate whether explicit phonetic training on English sounds and segments would be effective on reducing foreign accent of Arab ESL learners. Nine participants were divided into two groups: five in the experimental group and four in the control group. Thirteen English teachers at Saudi Universities who consisted of four native American English speakers and nine native British English speakers participated in the study as a rater of the productions of the participants. All participants in the experimental group and the control group received a total of 11 hours of pronunciation 
instruction throughout 11 weeks. Particular English sounds, /p, v, t f, I, y, e, æ, $\Lambda$, p, ว: \& 3:/, which were difficult for Arab ESL learners were selected based on the previous studies. The participants learned grapheme-phoneme correspondence and an articulatory phonetic description in terms of place and manner of articulation with the University of Iowa phonetics website. They listened to and repeated the sounds in isolation and in context, and they were informed that there is a comparison between Arabic and English regarding the sounds: Arab ESL learners substitute $/ \mathrm{p} /$ for $/ \mathrm{b} /$ and $/ \mathrm{f} /$ for $/ \mathrm{v} /$. The participants then moved on to practice these sounds in communicative activities. The participants were asked to produce five English sentences with the target sounds in their pre-and post-test: the process was that they read the sentences silently, they listened to the sentences recorded by English native speakers, and they recorded reading the five sentences. The results exhibited that there was no significant effect of phonetic training on the degree of perceived foreign accent.

Wong (2012) conducted a study to examine whether a High Variability Phonetic Training (HVPT) approach and a Low Variability Phonetic Training (LVPT) approach to training the perception and production of particular English sounds are beneficial to second language learners: "HVPT involves the use of natural training stimuli with various phonetic contexts produced by multiple speakers in an identification task with immediate feedback," and "LVPT adopts stimuli produced by one talker and in a single phonetic context." Sixtyfour secondary school students who were all Hong Kong residents speaking Cantonese as their first language participated in the research. The participants were divided into three groups; 22 of the participants were to receive the HVPT approach, 19 of them were to receive the LVPT approach, and 23 of them received no training as a control group. They have studied English for an average of 13.94 years. None of them had ever resided in English speaking countries. Seven native English speakers also participated in the research to produce stimuli for the tests and the training. Three phases of the procedure were provided to all of the 
three groups of the participants; the first phase was a pretest of one production test and one perception test, the second phase was a perceptual treatment of a total number of 10 training sessions except for the control group, and the last phase was a posttest of one perception test, one production test of contextualization, and two perception tests of generalization. A computer training program made by Wong (2012) was offered to the participants in all perceptual training and test sessions. In the pretest phase, the production test preceded the perception test to avoid any possibility for the participants to get any cueing. In the production test, the participants were given 60 words, 30 with / e/, 30 with / æ/, and 10 distractors. The participants were asked to record their productions of the words. In the perception test, the participants used a computer program made by the researcher to compete the test. They listened to the stimuli and chose the answer from three options. As a second phase, training was carried out to the HVPT group and the LVPT group. The HVPT group received a training that consisted of 60 stimuli produced by six different native English speakers. They were trained with a list of minimal pairs which is a two-alternative forced choice paradigm to help them pay more attention to the difference between the two vowels. During the training sessions, immediate feedback was provided to the participants, and their performance scores were also shown to them. The LVPT group received the same training procedure except for the fact that their 60 stimuli were produced by only one female native English speaker. As the last phase, in the posttest, the same production test and the perception test were given to the participants. As an addition to the posttest, a text of contextualization which consisted of a 250-word passage with 50 content words containing / e/ and / æ/ was given to the participants, and they were asked to record the whole passage as naturally as they can. A text of generalization which means 30 news words spoken by a new native English speaker were given to the participants with three choices of four choices being provided and one being open answer. They had to choose the correct answers. The other text of 
generalization was the same as the previous one except the fact that the 30 new words were produced by a familiar speaker whom the participants were exposed to during the training session.

The results showed that significant differences among groups were detected in the posttest. In the perceptual performance of the posttest, the HVPT and LVPT groups outperformed the control group. Between the two trained groups, the HVPT group performed better than the LVPT group. An interesting discovery was that the transfer of perceptual training to performance was limited and not significant. Wong (2012) concluded that HVPT and LVPT approaches, trainings in perception, were useful paradigms to different extents. The research displayed that phonetic training would help ESL learners to be aware of and perceive particular sounds of second language; however, the enhancement on the perception of the phonetic sounds would not directly transfer to better production of the phonetic sounds.

However, research by Saito (2013) obtained a result that explicit phonetic training is effective in enhancing pronunciation of ESL learners, which display a different result from the above studies. Saito (2013) conducted a study to see whether adding explicit phonetic information to focus on form instruction would enhance pronunciation of Japanese ESL learners of a particular sound, / $\mathbf{I} /$. Forty-nine students participated and were divided into three groups: focused form instruction + explicit instruction group (FFI+EI group), focused form instruction group (FFI group), and control group. Two experienced Native English speakers who worked in a language institute participated in the study as instructors. All participants of the three groups received a meaning-oriented lesson, which aimed at acquiring English argumentative skills that encompassed logical thinking, negotiation and debating skills, and public-speaking abilities. Every activity in the meaning-oriented lesson was created for the participants to be able to elicit the target sound. Each group received different 
instruction: FFI+EI group spent 5-10 minutes of their lessons on EI. As EI, the instructors provided their exaggerated pronunciation of / $\mathrm{x} /$ and $/ \mathrm{l} /$ and explained the relevant articulatory configuration for $/ \mathrm{I} /$, not for $/ 1 /$. Then the participants repeated after the instructors' pronunciation of / $\mathrm{I} /$, minimal pairs, and sentences with target words, which shows that the EI contained perception and production training. In their pre-and post-test, there were two different lexical groups: familiar items versus unfamiliar items. The results revealed that the participants in the FFI +EI group improved the pronunciation of / $\mathrm{I} /$ in both familiar and unfamiliar lexical contexts. The participants in the FFI only group enhanced their pronunciation of / $\mathrm{d} /$ in familiar lexicon, but not in unfamiliar lexicon. It concluded that FFI facilitates ESL learners' pronunciation; however, FFI alone is not as effective as adding EI to FFI. Thus, the study argues that explicit instruction of a L2 target sound is more helpful in helping ESL learners to improve pronunciation.

Lord (2005) also concluded that explicit phonetic training can help second language learners improve their pronunciation of L2. Seventeen English native speakers who learn Spanish participated in the research to evaluate whether an explicit phonetics course would help Spanish as a second language learners to improve on particular sounds: unaspirated $[\mathrm{p}, \mathrm{t}$, $\mathrm{k}$, the Spanish trilled [r], diphthongs within words and between words, and the fricative allophones, $[\beta, ð, \gamma]$. The participants were provided with an explicit phonetics class for a semester. The explicit phonetic training taught "standard instruction for an advanced phonetics course: textbook explanations of different articulations of English and Spanish sounds, oral practice, transcription practice, etc.” The phonetics course also frequently used incorporated voice analysis software to help the participants to notice and become more aware of different articulations. The participants were asked to record a reading excerpt before and after the phonetics course: the reading excerpt included not only target sounds, but also multisyllabic words and lexical items that the participants were not familiar with to make 
certain that they could concentrate on reading the excerpt as accurately as possible instead of recalling certain phonological rules. The results show that explicit instruction can be an effective tool even though statistically significant difference was not detected on all of the target sounds: no significant difference was detected on the unaspirated $[\mathrm{p}, \mathrm{t}, \mathrm{k}]$, whereas there were significant differences in the Spanish trilled [r], diphthongs within words and between words, and the fricative allophones, $[\beta, \gamma, \chi]$. The study argues that a phonetics class can raise second language learners' awareness of L1-L2 differences, and it could make improvements on their pronunciation.

However, Saalfeld (2011) replied to Lord's (2005) research raising a question of whether the improvements of Spanish target sounds derived from the phonetics course or from just being enrolled in Spanish courses. Lord's (2005) research was criticized because it did not have a control group which is needed to make certain where the participants' improvements came from. Saalfeld (2011) had 11 Spanish major or minor students as the experimental group and 17 Spanish major or minor students as the control group. All participants were taking Spanish courses; however, only the participants of the experimental group took a Spanish phonetics course by their interest. The participants recorded the same text as the one in Lord's (2005) study for their pre-and post-test to investigate whether they were able to produce accurate stress placement. The results revealed that the experimental group outperformed the control group even from the outset of the experiment. The experimental group also produced more accurate stress placement than the control group even in post-test. There was a significant difference between groups; however, there was no significant difference between the pre-test and the post-test of the experimental group. The researcher suggested that the derived results was probable due to the fact that the participants in the experiment group were already more interested in improving their pronunciation which was supported by the fact that they chose to take the phonetics course. The researcher also 
suggested that the ceiling effect might influence the results because the participants in the experimental group already had high proficiency on the pre-test. Saalfeld (2011) concluded that second language learners who need a phonetics class were not enrolled in phonetics course, which means that second language learners who have not achieved high proficiency yet did not choose to attend a phonetics class out of their own interest.

It was obvious that no matter what ESL learners' first language is, various L1s influence on ESL learners' pronunciation of English in different ways (Leahy, 1980) because ESL learners perceive the sounds of English through their L1, and very few ESL learners are aware of the influence of their L1 on pronunciation of English. Most ESL learners tend to consider that pronunciation problems derive from personal weaknesses, not from the influence of their L1s (Cenoz \& Lecumbeni, 1999). There is also considerable amount of research on how ESL learners perceive and acknowledge their pronunciation difficulties. In addition, even though there are some studies on the effectiveness of the phonetic training, the studies display contradictory results on the effectiveness of the phonetics training: some argue that it is effective, whereas others argue that it is not effective.

The researcher found out a gap between these two areas of study, i.e., L1 influence on L2 pronunciation and the effectiveness of phonetics training. The researcher believed that there is a need to identify whether ESL learners are able to perceive particular L2 sounds that are either non-existent or non-contrastive in their first language. Moreover, whether ESL learners learning why particular L2 sounds are difficult and how to produce correct L2 sounds in terms of place and manner of articulation and voicing through explicit phonetics training could be beneficial for ESL learners to improve their L2 pronunciation. The selected first language for this study was Korean because Korean and English differ very much, so Korean ESL learners are assumed to have quite severe pronunciation problems (Avery \& 
Enrlich, 2000); however, there is not much study on pronunciation of Korean ESL learners. Thus, the present study will examine the effectiveness of phonetic training with native Korean Speakers on whether teaching particular pairs of English sounds that are considered as difficult L2 sounds due to the different sound systems of L1 and L2 would lead to better perception and production. Most native Korean ESL learners would have difficulty with particular pairs of sounds such as /b/-/v/, /p/-/f/, /s/-/ /, and /r/-/l/ due to the severe differences between the sound systems of Korean and English (Avery \& Enrlich, 2000). The purpose of the study is to investigate Korean ESL learners' ability to distinguish the pairs of these particular sounds, /b/-/v/, /p/-/f/, /s/-/s/, and /r/-/l/. Furthermore, I will investigate whether phonetic training would lead to better perception of the sounds differences and enhance production accuracy in a natural context.

Following are the research questions:

1. Can Korean ESL learners distinguish between the sounds that are contrastive in English, but are non-existent or non-contrastive in Korean? (i.e., /b/-/v/, /p/-/f/, /s/-/s/, and /r/-/1/)

2. Does explicit training lead to more accurate perception of these English sounds?

3. Does the explicit training lead to more accurate production of these English sounds?

To answer these questions, twelve Korean ESL learners received two hours of a phonetics training on four pairs of L1-related difficult L2 English sounds to see whether they would benefit from the explicit phonetics training in their perception and production of the sounds. 


\section{Methods}

This chapter will introduce who the participants are, why particular pairs of English sounds were selected, what materials were created and used for phonetic training, how this study was designed, and how the production of the data were collected and evaluated.

\section{Participants}

To conduct the research, a group of twelve native Korean ESL learners participated in two hours of phonetic sessions. The participants were gathered through convenience sampling. The researcher has known all of the participants for a while, and the participants were accessible because of the fact that the researcher and the participants were living in the same area. The participants were invited to participate in the research by the researcher, and they willingly did so. The age of the native Korean ESL learners varied from early teenage to early forties. Among the twelve participants, seven participants were students, two participants worked in academic-related fields as a researcher and a professor, and three of them were homemakers. Their length of residence in the United States or English speaking countries was different. It varied from six months to more than five years. All of the participants were living in the U.S during the time of the experiment.

\section{Selection of the Sounds for Instruction}

The following four pairs of English sounds were selected to test whether phonetic training would be beneficial for Korean ESL learners: /b/-/v/, /p/-/f/, /s/-/ /, and /r/-/1/. Avery and Ehrlich (2000) introduced the predictable pronunciation problems of Korean ESL learners in Teaching American English Pronunciation: "Korean has few word-final consonants and lacks both initial and final consonant clusters. Voicing in Korean is quite different from voicing in English and Korean speakers can have difficulty with the 
voiced/voiceless distinction" (p. 138). Then Avery and Ehrlich (2000) introduced specific problems in terms of consonants, vowels, stress, rhythm, and intonation. The four pairs, /b/-/v/, /p/-/f/, /s/-/s/, and /r/-/l/, were especially selected by the researcher because the researcher believes that it is easier to improve consonants than vowels, and the pairs are indeed the noticeable mistakes that Korean ESL learners make from her experience. Avery and Ehrlich (2000) explained that /b/-/v/ and /p/-/f/ are problematic because "Korean does not have the sounds /f/ and /v/, and Korean speakers tend to substitute /p/ and /b/, respectively". These first two pairs are regarding the lack of the phoneme in their L1, Korean. $/ \mathrm{s} /-/ \mathrm{J} /$ is problematic because "in Korean, /s/ is pronounced as either / $/$ /before high and mid front vowels) or as aspirated /s/ in most other positions. Thus, words such as 'seat' and 'sheet' may sound the same (like 'sheet'). Furthermore, words in which learners substitute their aspirated /s/ will sound quite odd to the English ear" (Avery \& Ehrlich, 2000). The last pair, / $\mathrm{r} /-/ 1 /$, is also problematic because "Korean students tend to substitute /1/ for $/ \mathrm{r} /$ in initial position, producing 'light' instead of 'right'. Alternatively, they may substitute what sounds like an /r/ or a flap /D/ for /1/ between vowels, producing 'firing' or 'fighting' for 'filing' (Avery \& Ehrlich, 2000). The other two pairs are regarding allophones. The four sounds in two pairs are different phonemes in English; however, /r/-/1/ are allophones of the same phoneme, ᄅ, /r/, in Korean, and /s/-/S/ are also allophones of the same phoneme, ᄉ, /s/, in Korean; / $/$ / occurs before $/ \mathrm{i} /$, and /s/ is for other vowels in Korean. $/ \mathrm{r} /$ occurs between vowels, and /1/ is for elsewhere in Korean. Thus, these four particular pairs will be examined in the study.

\section{Training Materials}

The phonetic training sessions occurred two times. Each session went on for an hour. The objective of the first session was for the participants to acquire the concept of place 
of articulation, manner of articulation, and voicing (see Appendix E). The concepts were briefly explained; however, they were taught for the participants to be able to have background knowledge regarding phonetics. Another objective of the first session was for the participants to learn place of articulation, manner of articulation, and voicing of the particular minimal pairs of /b/-/v/ and /p/-/f/ and practice them. The objectives of the second session was for the participants to learn place of articulation, manner of articulation, and voicing of the particular minimal pairs of /s/-/ $/, / \mathrm{r} /-/ 1 /$. Another objective of the second session was that the participants practice the new pairs of $/ \mathrm{s} /-/ \int /, / \mathrm{r} /-/ 1 /$, and they review the four pairs and practice on the four pairs. The concepts were presented with PowerPoint that contained explanations from the book of Avery and Ehrlich, 2000. The participants were also provided with visual aids from the University of Iowa website (www.soundsofspeeech.uiowa.edu $)$ to be able to receive more detailed information.

The participants were taught that the place of articulation in general was where the airstream is obstructed in the formation of consonants, and there are six places where it can happen for English sounds. Then they were given a phonetic symbol as an example of each place of six places and practiced words containing the sounds to feel to experience how the lips and the tongue moved. For example, the English sound /p/ was given to practice bilabial, and the word 'put' was given. Once the practice was done, the participants moved on to the next concept, the manner of articulation in general. They were taught that the manner of articulation refers to the way in which the obstruction of the air-stream is achieved. There are six ways including glides. The participants were given a phonetic symbol as an example for each way; for example, the English sound /p/ was given to practice stops. They practiced the words to experience manner. The participants went on and learned a concept of voicing. They were guided to put their hands on their vocal cords and pronounce some of the voiced and some of the voiceless sounds, and they were told that the difference between the voiced and 
the voiceless was the existence of vibration; if there is vibration, the sound is voiced, and if there is not, it is voiceless. The participants practiced some of the voiced and voiceless sounds. It took 30 minutes of the first session.

Then they were led to examine two particular minimal pairs of $/ \mathrm{b} /-/ \mathrm{v} /$ and $/ \mathrm{p} /-\mathrm{f} /$. First, they studied the pair of $/ \mathrm{b} /$ and $/ \mathrm{v} /$ in terms of place of articulation, manner of articulation, and voicing for ten minutes. $/ \mathrm{b} /$ and $/ \mathrm{v} /$ differed in place of articulation and manner of articulation; /b/ is produced with both lips, and it is complete obstruction. $/ \mathrm{v} /$ is produced with the lower lip and upper teeth and with a partial obstruction. Once the participants were aware of the differences between the pair of $/ \mathrm{b} /$ and $/ \mathrm{v} /$, they studied another pair which is /p/ and /f/ in terms of place of articulation, manner of articulation, and voicing for another ten minutes. The pair of $/ \mathrm{p} /$ and /f/ also differed in place and manner of articulation; /p/ is produced with both lips and with a complete obstruction. /f/ is produced with the lower lip and upper teeth and with a partial obstruction. Learning the two pairs took twenty minutes, ten minutes each for $/ \mathrm{b} /-/ \mathrm{v} /$ and $/ \mathrm{p} /-/ \mathrm{f} /$ respectively.

The participants were then provided with a few activities to practice the two particular minimal pairs for ten minutes (see Appendix F). The activities consisted of three exercises. The first exercise was for the participants to listen to recordings of ten minimal pair words of $/ \mathrm{b} /-/ \mathrm{v} /$ and $/ \mathrm{p} /-/ \mathrm{f} /$ and circle each word that they think they have heard. For example, there was a pair of fashion /f/ and passion /p/, they listened to the recording, and they chose the word heard was either the word with /f/ or the word with /p/ based on what they think they have heard. The second exercise was a pair work task. Each participant in pairs received a different chart of minimal pair words with $/ \mathrm{b} /-/ \mathrm{v} /$ and $/ \mathrm{p} /-/ \mathrm{f} /$. For example, if a participant had the word 'pair,' the other participant had the word 'fair.' Each participant took turns and produced a word from their list, and the other participant produced a word that they think 
they have heard deciding what sound the word had from the minimal pairs of $/ \mathrm{b} /-\mathrm{v} / \mathrm{and}$ /p/-/f/. Then the participant who provided the word corrected by the other participant if the participant made a wrong pronunciation. The pairs kept doing this exercise until they finished both of the charts completely. The last exercise was to use a 'voice-controlled personal digital assistant' of the smartphone. Each participant received ten words from the minimal pairs of /b/-/v/ and /p/-/f/. The participants said a frame sentence of 'show me a picture of For example, there was a word, vest with /v/. If the participants said the sound /v/ correctly, then the participants could get a picture of a vest. If the participants mispronounced the sound $/ \mathrm{v} /$, there was a probability that the participants might get a picture of best with $/ \mathrm{b} /$. They marked how many pictures they have got right, which showed how much their pronunciation of each word was correct. The phonetic concepts and the activities regarding the two pairs, /b/-/v/ and /p/-/f/ were carried out in the first session.

The second session consisted of the brief review of the phonetic concepts, separate activities regarding the new two pairs, /s/-/ $/$ and /r/-/1/, and an additional activity for the entire four pairs. The participants reviewed the concepts of the place of articulation, manner of articulation, and voicing for the first ten minutes (see Appendix E). Then they were guided to examine another two particular minimal pairs of /s/-/ $/$ and /r/-/1/. First of all, they studied the pair of $/ \mathrm{s} /$ and $/ \mathrm{J} /$ in terms of place of articulation, manner of articulation, and voicing for ten minutes. $/ \mathrm{s} /$ and $/ \mathrm{J} /$ differed in place of articulation; $/ \mathrm{s} /$ is produced with the tip of the tongue and the tooth ridge. $/ \mathrm{J} /$ is produced with the blade of the tongue and the hard palate. Once the participants were aware of the differences between the pair of $/ \mathrm{s} /$ and $/ \mathrm{J} /$, they studied another pair which is $/ \mathrm{r} /$ and $/ 1 /$ in terms of place and manner of articulation, and voicing for another ten minutes. The pair of $/ \mathrm{r} /$ and $/ 1 /$ does not differ in place and manner of articulation, and voicing; both /r/ and /1/ are produced with the tip of the tongue and the tooth ridge, the air passes through the mouth in a somewhat fluid manner (liquids), and they are 
voiced. The pair of $/ \mathrm{r} /$ and / $/$ is very challenging to Korean ESL learners because / $\mathrm{r} /$ and /1/ are transcribed into a single letter, ᄅ, in Korean.

The participants were then provided with the same few activities as in session 1 to practice the two particular minimal pairs for twenty minutes (see Appendix F). The activities consisted of three exercises. The first exercise was for the participants to listen to recordings of ten minimal pair words $/ \mathrm{s} /-/ \int /$ and $/ \mathrm{r} /-/ 1 /$ and circle each word that they think they have heard. For example, there was a pair of save /s/ and shave / /; they listened to the recording, and they chose if the word heard was either the word with /s/ or the word with / $/$ based on what they think they have heard. The second exercise was pair work. Each participant in pairs received a different chart of minimal pair words of $/ \mathrm{s} /-/ \int /$ and $/ \mathrm{r} /-/ 1 /$. For example, if a participant had the word 'chic', the other participant had the word 'seek'. Each participant took turns and produced a word from their list, and the other participant produced a word that they think they have heard deciding what phonetic sound the word had from the minimal pairs of $/ \mathrm{s} /-/ \int /$ and $/ \mathrm{r} /-/ 1 /$. Then the participant who provided the word corrected the other participant if the participant made a wrong pronunciation. The pairs kept doing this exercise until they finished both of the whole charts. The last exercise was to use 'voice-controlled personal digital assistant' of smartphone. Each participant received ten words from the minimal pairs of $/ \mathrm{s} /-/ \mathrm{J} /$ and $/ \mathrm{r} /-/ 1 /$. The participants said a frame sentence of 'show me a picture of '. For example, there was a word, road with $/ r /$. If the participants said the sound $/ \mathrm{r} /$ correctly, then the participants could get a picture of road. If the participants mispronounced the sound $/ \mathrm{r} /$, there was a probability that the participants might get a picture of load with $/ l /$. They marked how many pictures they have got right, which showed how much their pronunciation of each word was correct. 
As a review exercise for the total of the four pairs, an additional activity was given to the participants for them to be able to practice all of the four pairs. Three pictures were provided with short questions that are made aiming to have the participants produce the four pairs. The pairs could spend up to twenty minutes for the additional activity to practice all of the four pairs; however, it was recommended to finish the additional activity within five minutes and to go back to the previous activities and practice a specific pair that they feel they had the most difficulty with.

\section{Instruments}

The current study is a pre-post test design without a control group. The current study quantitatively and qualitatively explores whether explicit phonetic training has an effectiveness on perception and production of Korean ESL learners regarding sound contrasts that they do not have in the L1. The independent variable is the treatment that is 2 hours of phonetics classes for two weeks. The dependent variables are accuracy in perception and production of the sounds in training. The participants had the same assessment for pre-test and post-test. The perception was evaluated through distinguishing minimal pairs in recordings. The participants listened to a pair of words which came from the pairs of $/ \mathrm{b} /-/ \mathrm{v} /$, / $\mathrm{p} /-/ \mathrm{f} /, / \mathrm{s} /-/ \int /$, and /r/-/1/. Then, they marked whether the words are the same or different. The participants also listened to a word from the pairs of $/ \mathrm{b} /-/ \mathrm{v} /, / \mathrm{p} /-/ \mathrm{f} /, / \mathrm{s} /-/ \mathrm{s} /$, and $/ \mathrm{r} /-/ 1 /$, and they chose what sound they thought they had heard from each pair. These two tasks showed whether they were able to perceive the different sounds of English or not. The production was evaluated through a self-recording of pairs of words and an interview with a Native American English Speaker. Two Native American English speakers evaluated the participants' productions of the pre/post-test. 
There are four tasks in the pre-test and post-test. The first task is to distinguish minimal pairs (see appendix A). The participants listen to sixteen pairs of words. Once the participants heard each pair of words, they mark whether the words heard are the same or different; if the participants listen to the pair of berry $/ \mathrm{b} /-$ very $/ \mathrm{v} /$ and are able to distinguish the difference, they would mark different. If the participants listen to the pair of ban /b/- ban / $\mathrm{b} /$ and are able to figure out the words are the same, they would mark the same. This task evaluates whether the native Korean ESL learners are able to perceive the different sounds. For example, if they are able to perceive the sounds of the words correctly, they would be able to mark whether the pairs are the same or different. The task was objectively scored as right or wrong. Each correct answer was awarded one point and an incorrect answer was 0 point. The maximum possible number of points are 16 points while the minimum being 0 point.

The second task is to listen to each word from the list of sixteen words and choose the correct phonetic symbol that they think they have heard (see Appendix B). The list of the words consists of a part of a minimal pair. For example, the participants listen to a word 'ban', and they are asked to mark whether the word that they have heard is either 'ban' or 'van'. This task allows the researcher to evaluate whether they can perceive the different sounds correctly and choose appropriate ones from the options. The task was objectively scored as right or wrong. Each correct answer was awarded one point and an incorrect answer was 0 point. The maximum possible number of points are 16 points while the minimum being 0 point.

The third task is to record the minimal pairs given a list of sixteen minimal pairs (see Appendix C). For example, a minimal pair such as rain /r/- lane /1/ was given for the participants to record. This task enables the researcher to evaluate whether the participants 
are able to produce the different sounds correctly. This is intended to show whether their ability to perceive the different sounds can transfer to their production of the sounds. The two American English Native speakers evaluated the accuracy of each word of the sixteen pairs. All of the words produced are graded as accurate ( 2 points), comprehensible ( 1 point), or inaccurate ( 0 point). Then the scores of how many words each participant has correctly produced are changed to a percentage. It should be mentioned that the inter rater-reliability was 0.88 for pre-test and 0.7 for post-test.

The last task is picture description with an American English Native speaker to evaluate whether the participants can actually make improvements in their production of the targeted English sounds (see Appendix D). The interviewer and each participant have the same picture, and each participant describe the picture with as much detail as they can. The interview is carried out in a very casual and comfortable atmosphere to derive natural spontaneous speech from the participants. The two American English Native speakers evaluated the accuracy of each word containing the target sounds; /b/-/v/, /p/-/f, /s/-/s/, and $/ \mathrm{r} /-/ 1 /$. Due to the different numbers of the words generated by each participant, all of the words produced are graded as accurate ( 2 points), comprehensible (1 point), or inaccurate (0 point). Then the scores of how many words each participant has correctly produced are changed to percentage. It should be mentioned that the inter-reliability was very low for task 4 of pre-test and post-test. The inter rater-reliability was 0.18 for pre-test and 0.42 for posttest.

\section{Data Collection Procedures}

The group of twelve Korean ESL learners took a pre-test on the first day of the data collection procedures, a day right before the first phonetic treatment session of the two-week phonetic treatment sessions. The pre-test and the first session of a phonetic training happened 
in the same week. The second phonetic treatment session was given to the participants a week after the first phonetic treatment session. A post-test was conducted a day after the second phonetic treatment session. The second phonetic treatment session and the post-test were supposed to be in the same week, but a few participants had to have the post-test after a week of the second phonetic treatment session. 


\section{Results}

The study is designed to evaluate whether explicit phonetic training would be beneficial to improve perception and pronunciation of ESL learners on L2 English sounds. Twelve Korean ESL learners were provided with two hours of phonetic training on the particular pairs of English sounds (i.e., /p/-/f/, /b/-/v/, /s/-/ $/$, and /r/-/l/). The participants took pre-and post-tests to compare the effectiveness of the phonetic training. This chapter will reveal the results answering the research questions. Table 2 is the descriptive statistics.

Table 2

Mean Scores and Standard Deviation of Pre-test and Post-test

\begin{tabular}{lllll}
\hline Tasks & Tests & $\mathrm{N}$ & Mean & $\begin{array}{l}\text { Standard } \\
\text { Deviation }\end{array}$ \\
\hline Task 1 & Pretest & 12 & 12.58 & 1.38 \\
& Posttest & 12 & 13.08 & 1.24 \\
Task 2 & Pretest & 12 & 14.75 & 1.66 \\
& Posttest & 12 & 14.75 & 1.06 \\
Task 3 & Pretest & 12 & 61.29 & 3.02 \\
& Posttest & 12 & 62.08 & 2.37 \\
Task 4 & Pretest & 12 & 97.13 & 1.46 \\
& Posttest & 12 & 96.42 & 2.35 \\
\hline
\end{tabular}

Note: $\mathrm{N}=$ Number of Participants

RQ1. Can Korean ESL learners distinguish between the sounds that are contrastive in English, but are non-existent or non-contrastive in Korean? (i.e., /b/-/v/, / $\mathbf{p} /-/ \mathbf{f} /, / \mathbf{s} /-/ \mathbf{f} /$, and $/ \mathbf{r} /-/ \mathbf{l} /)$

The perception of Korean ESL learners on the target sounds was evaluated in Task 1 and Task 2 of the pre-test: Task 1 was for the participants to listen to 16 pairs of words and to determine whether they are the same or different, and Task 2 was for the participants to listen to 16 words and to pick a right phonetic symbol from the options. Only the pre-test scores were used to answer the question whether the learners are able to perceive the different sounds without any influence of training. The mean score of Task 1 was 12.58 out of 16 , 
which is $79 \%$. The mean score of Task 2 was 14.75 out of 16 , which is $92 \%$. These mean scores are relatively high, which shows that the participants were able to perceive these English sounds although they are different from the Korean phonetic system.

\section{RQ2. Does explicit training lead to more accurate perception of these English}

\section{sounds?}

Whether explicit phonetic training would affect the perception of Korean ESL learners was evaluated by comparing the pre-test and post-test of Task 1 and Task 2 . The mean score of Task 1 in the pre-test was 12.58 , and the mean score of Task 1 in post-test was 13.08. The mean score of Task 2 in pre-test was 14.75, and the mean score of Task 2 in posttest was also 14.75. Paired-samples t-tests were conducted on the pre-test and post-test of the two tasks, and they did not exhibit significant differences $(\mathrm{p}>0.05)$. The mean scores of Task 2 were even the same. Thus, the explicit phonetic training did not lead to more accurate perception of Korean ESL learners.

\section{RQ3. Does the explicit training lead to more accurate production of these}

\section{English sounds?}

Whether explicit phonetic training would affect production of Korean ESL learners was evaluated by comparing the pre-test and post-test scores of Task 3 and Task 4: Task 3 was for the participants to produce 16 pairs of words, and Task 4 was for the participants to describe a picture giving as much detail as they can. The mean score of Task 3 in the pre-test was 61.29 , and the mean score of Task 3 in post-test was 62.08 . The mean score of Task 4 in the pre-test was 97.13 , and the mean score of Task 4 in the post-test was 96.42 . This shows that the mean score even got lowered in post-test in the case of Task 4. Paired samples t-tests were conducted on the pre-test and post-test of the two tasks, and no statistical significance 
was detected $(p>0.05)$. Thus, the explicit phonetic training did not lead to more accurate production of Korean ESL learners. 


\section{Discussion}

\section{Summary of Findings}

Korean ESL learners were able to perceive English sounds that are different from Korean. These learners had the ability to perceive the sounds before the explicit phonetic training: based on the average pre-test scores of $79 \%$ on Task 1 and $92 \%$ of Task 2 . Whether the explicit phonetic training would lead to more accurate perception of the target sounds was evaluated by comparing the mean scores of Task 1 and Task 2 in the pre-and post-tests. There was no significant difference, which implies that the learners did not benefit from the explicit phonetic training in terms of accuracy in perception. The comparison between the mean scores of Task 3 and Task 4 in the pre-and post-test exhibited that there was no significant difference in terms of the accuracy in the production. This shows that the explicit phonetic training did not help the learners to improve the production of the target sounds.

\section{Previous Studies on Explicit Phonetic Training}

A few studies have been trying to evaluate whether explicit phonetic training is effective on improving pronunciation of ESL learners; however, these previous studies display contradictory results. Some studies have concluded that explicit phonetic training does not have any impact on influencing pronunciation of second language learners (Kissling, 2013; Algethami, 2017; Wong, 2012) whereas a few studies have shown that explicit phonetic training does enhance pronunciation of second language learners (Saito, 2013; Lord, 2005). Kissling (2013) established a study to investigate whether there is a different degree of improvement on productions of a variety of problematic consonants by English speakers learning Spanish due to explicit pronunciation instruction versus implicit treatment. It turned out that there was no significant difference on production of the experimental group and the control group. Kissling (2013) concluded that the explicit pronunciation instruction was not 
advantageous in improving pronunciation of second language learners. The current study confirmed this finding. Another study exhibited that phonetic training does not only provide no benefit on enhancing pronunciation, but also gives no advantage on reducing foreign accent. Algethami (2017) also found that explicit phonetic training was not effective in reducing the degree of perceived foreign accent from his research in which Arab ESL learners were taught problematic English sounds. The participants took pre-and post-tests on the target sounds, and the comparison of the production did not produce significant differences. Wong (2012) investigated whether the different types of phonetic training affect the improvements of ESL learners' pronunciation differently; the types of phonetic training consisted of High Variability Phonetic Training (HVPT) and Low Variability Phonetic Training (LVPT). HVPT provides various phonetic contexts by multiple speakers whereas LVPT provides a single phonetic context by one speaker. Wong (2012) discovered that either of phonetic training would improve ESL learners' perception compared to the control group receiving no phonetic training while phonetic training with various contexts would help ESL learners to improve more than phonetic training with a restricted context. Despite the effectiveness of the phonetic training for perception, there was no significant impact on the production of ESL learners, which yielded a conclusion that phonetic training does not affect pronunciation of ESL learners.

However, research by Saito (2013) suggests that phonetic training has an impact on improving pronunciation of ESL learners. Saito (2013) argues that when ESL learners are provided with explicit phonetic instruction while receiving focused form instruction, the explicit phonetic instruction helps the learners to produce improved pronunciation of the target sound. Lord (2005) also suggested that pronunciation is teachable and possible to be improved on particular sets of second language sounds through a phonetic course. 
Even though the previous studies present contradictory results of the effectiveness of phonetic training, most of the research concludes that the explicit phonetic training is not effective to help ESL learners to improve their L2 English pronunciation, which the current study agrees with. It confirms that the explicit phonetic training does not benefit either perception or production of ESL learners on L2 English sounds that are difficult due to the different systems of L1 and L2. There could be multiple reasons of why explicit phonetic training is not effective: Kissling (2013) suggested that longer instructional treatment might bring improvements in pronunciation, and Algethami (2017) reported that the use of a small sample size was limitation of his study. Wong (2012) recommended that "lengthened, more intensive, or sentence-level training" should be tested by future studies to see whether phonetic training would improve pronunciation of ESL learners. The current study displays similar weaknesses as other previous studies had: it had a small sample size, and it did not have lengthened phonetic training.

\section{Implications}

The current study came to the conclusion that explicit phonetic training on L2 English sounds is not effective on enhancing both of ESL learners' perception and pronunciation. This raises a need to find different means to help ESL learners improve on their pronunciation because pronunciation is an important factor in comprehensibility (Derwing, 2013), and ESL learners want to improve their L2 pronunciation, thinking that their pronunciation causes communication breakdowns (Derwing and Rossiter (2002). Guiding ESL learners to improvements on pronunciation is a valuable aid. Another approach for instruction might be needed. Instead of metalinguistics, other instruction such as giving personalized feedback, providing native-like structured input to raise their awareness, and having them analyze peer Korean ESL learners for self-realization might be more effective 
and helpful. Another suggestion for possible improvement on L2 English pronunciation derives from the study by Saito (2013); Saito (2013) identified that focus on form instruction with explicit instruction did help Japanese ESL learners to improve a particular sound, / $\mathrm{I} /$ in both of familiar and unfamiliar lexicon. Phonetics training that offers explicit instruction in communicative context might open a possibility for improvement on L2 English pronunciation. If a communicative context where participants are led to practice and elicit the target sounds by some detailed help made by a teacher is given to the participants from phonetics training, it might bring more benefits to ESL learners. Focused and manipulated contexts in explicit phonetic training would drive participants to focus and practice only on target sounds in isolation, which does not reflect real communicative situations. The communicative contexts would allow participants to apply the phonetic knowledge and information learned to their productions for actual use, not for practice itself.

\section{Limitations}

The present study had several limitations. The study was carried out with a small number of participants, 12 , and most of the participants already had an intermediate proficiency level, which was revealed by the results of pre-test. Some of the participants did not consistently join the phonetics class, which means a few were late or missed one phonetic session, so they had a time to receive brief explanations from the researcher as a substitution of being late or absent. The instructional time period was also too short to correct pronunciation issues of each participant. The interrater reliability of Task 4 was very low, i.e., 0.18 for the pre-test and 0.42 for the post-test. The raters did not receive any type of training before they graded the tasks. The lack of certain criteria or standard for grading might have caused the low interrater reliability of Task 4 . Another possible reason for the low interrater is that the graders have different experience in teaching. One rater is a very experienced ESL 
instructor who has been teaching almost for thirty years, whereas the other rater is a relatively new instructor.

\section{Future Directions}

Future studies that want to find out the efficacy of explicit phonetic training should consider exploring larger number of participants, and exposing them with a longer time period of phonetic training. Researchers should make certain that the participants must be consistent on time and attendance to acquire more solid results. The phonetic training would be more beneficial if it has an independent session to provide more information in detail regarding L2 target sounds in terms of place of articulation, manner of articulation, and voicing. Having more time to practice in natural, communicative contexts would lead learners to acquire the target sounds and more naturally produce them. 


\section{References}

Algethami, G. (2017). The effects of explicit pronunciation instruction on the degree of perceived foreign accent in the speech of EFL learners, Research in Language, 15(3), 253-263.

Atli, I., \& Bergil, A. (2012). The effect of pronunciation instruction on students' overall speaking skills. Procedia - Social and Behavioral Sciences, 46, 3665-3671.

Avery, P., \& Ehrlich, S. (2000). Teaching American English pronunciation (Oxford handbooks for language teachers). Oxford: Oxford University Press.

Anderson-Hsieh, J., \& Venkatagiri, H. (1994). Syllable duration and pausing in the speech of Chinese ESL speakers. TESOL Quarterly, 28(4), 807-812.

Cenoz, J., \& Lecumberri, M. (1999). The acquisition of English pronunciation: Learners' views. International Journal of Applied Linguistics, 9(1), 3-15.

Chan, A. (2011). The perception of English speech sounds by Cantonese ESL learners in Hong Kong. TESOL Quarterly: A Journal for Teachers of English to Speakers of Other Languages and of Standard English As a Second Dialect, 45(4), 718-748.

Derwing, T. (2003). What do ESL students say about their accents? Canadian Modern Language Review, 59(4), 547-66.

Derwing, T., \& Rossiter, M. (2002). ESL learners' perceptions of their pronunciation needs and strategies. System, 30(2), 155-166. 
Flege, J., Frieda, E., \& Nozawa, T. (1997). Amount of native-language (L1) use affects the pronunciation of an L2. Journal of Phonetics, 25(2), 169-186.

Gorman, B., \& Gillam, R. (2003). Phonological awareness in Spanish: A tutorial for speech-language pathologist. Communication Disorders Quarterly, 25(1), 13-22.

Grami, G. M. A., \& Alzughaibi, M. G. (2012). L1 transfer among Arab ESL learners: Theoretical framework and practical implications for ESL teaching. Theory and Practice in Language Studies, 2(8), 1552-1560.

Han, J., Hwang, J., \& Choi, T. (2011). The acquisition of phonetic details: Evidence from the production of English reduced vowels by Korean learners. Second Language Research, 27(4), 535-557.

Kang, O. (2015). Learners' perceptions toward pronunciation instruction in three circles of world Englishes. TESOL Journal, 6(1), 59-80.

Kim, H., \& Billington, R. (2018). Pronunciation and comprehension in English as a lingua franca communication: Effect of L1 influence in international aviation communication. Applied Linguistics, 39(2). 135-158.

Kissling, E. (2013). Teaching pronunciation: Is explicit phonetics instruction beneficial for FL learners? The Modern Language Journal, 97(3), 720-744.

Leahy, R. (1980). A practical approach for teaching ESL pronunciation based on distinctive feature analysis. TESOL Quarterly, 14(2), 209-19. 
Lord, G. (2005). (How) Can we teach foreign language pronunciation? On the effects of a Spanish phonetics course. Hispania, 88(3), 557-567.

Macdonald, D., Yule, G., \& Powers, M. (1994). Attempts to improve English L2 pronunciation: the variable effects of different types of instruction. Language Learning, 44(1), 75-100.

Mitchell, R., Myles, F., \& Marsden, E. (2013). Second Language Learning Theories. London: Routledge.

Morley, J. (1991). The pronunciation component in teaching English to speakers of other languages. TESOL Quarterly, 25(3), 481-520.

Saalfeld, A. (2011). Acquisition of L2 phonology in advanced learners: does instruction make a difference? Second Language Learning and Teaching Conference, 144-152.

Saha, S., \& Das Mandal, S. (2016). English lexical stress produced by native (L1) Bengali speakers compared to native (L1) English speakers: An acoustic study. International Journal of Speech Technology, 19(4), 827-840.

Saito, K. (2013). Reexamining effects of form-focused instruction on L2 pronunciation development. Studies in Second Language Acquisition, 35(01), 1-29.

Scales, J., Wennerstrom, A., Richard, D., \& Wu, S. (2006). Language learners' perceptions of accent. TESOL Quarterly: A Journal for Teachers of English to Speakers of Other Languages and of Standard English As a Second Dialect, 40(4), 
$715-738$.

Wong, J.W.S. (2012). Training the Perception and Production of English / e/ and / æ/ of Cantonese ESL Learners: A Comparison of Low vs. High Variability Phonetic Training. In Proceedings of the $14^{\text {th }}$ Australasian International Conference on Speech Science and Technology. Sydney, Australia (pp.3-6).

Yoo, A.J. (2012). A look at the attitudes some Korean university students have towards different accents in English. Journal of International Education Research, 8(2), 155164. 


\section{APPENDIX A}

Instruction: You will hear sixteen pairs of words. Please indicate whether the words in each pair are the same or different. An example will be given by the teacher.

1. Same Different

2. Same Different

3. Same Different

4. Same Different

5. Same Different

6. Same Different

7. Same Different

8. Same Different

9. Same Different

10. Same Different

11. Same Different

12. Same Different

13. Same Different

14. Same Different

15. Same Different

16. Same Different 


\section{APPENDIX A}

\section{Discrimination Task: Distinguish the sounds}

Teacher's guideline: a native speaker of American English will record the pairs, and participants will listen to the recording and discriminate the sound.

1. berry-very /b/-/v/ different

2. ban-van /b/-/v/ different

3. vowels-vowels /v/-/v/ same

4. bat-bat $/ \mathrm{b} /-/ \mathrm{b} /$ same

5. faint-faint /f/-/f/ same

6. feel-peel /f/-/p/ different

7. frank-prank /f/-/p/ different

8. pull-pull /p/-/p/ same

9. sift-shift /s/-/ / different

10. sake-sake /s/-/s/ same

11. sip-ship /s/-/ / different

12. show-show $/ \int /-/ \int /$ same

13. lubber-rubber /1/-/r/ different

14. lug-rug /1/-/r/ different

15. reap-reap $/ \mathrm{r} /-/ \mathrm{r} /$ same

16. lead-lead /1/-/1/ same 


\section{APPENDIX B}

Instruction: You will hear sixteen words. Circle the first sound you hear in each word. An example will be given by the teacher.

1. $/ \mathrm{b} /$ or $/ \mathrm{v} /$

2. $/ \mathrm{s} /$ or $/ \mathrm{S} /$

3. $/ \mathrm{p} /$ or $/ \mathrm{f} /$

4. $/ \mathrm{b} /$ or $/ \mathrm{v} /$

$5 . / \mathrm{p} /$ or $/ \mathrm{f} /$

6. $/ \mathrm{s} /$ or $/ \mathrm{s} /$

7. $/ \mathrm{s} /$ or $/ \mathrm{s} /$

$8 . / \mathrm{p} /$ or $/ \mathrm{f} /$

9. $/ \mathrm{b} /$ or $/ \mathrm{v} /$

10. $/ 1 /$ or $/ \mathrm{r} /$

11. $/ 1 /$ or $/ \mathrm{r} /$

12. $/ \mathrm{p} /$ or $/ \mathrm{f} /$

13. $/ \mathrm{b} /$ or $/ \mathrm{v} /$

14. $/ 1 /$ or $/ \mathrm{r} /$

$15 . / \mathrm{s} /$ or $/ \mathrm{J} /$

16. $/ 1 /$ or $/ \mathrm{r} /$ 


\section{APPENDIX B}

\section{Identification Task: Find the right sound}

Teacher's guideline: a native speaker of American English will record reading the word, and participants will listen to the record and identify the sound.

1. buy /b/

2. sheet $/ \mathbf{J} /$

3. past /p/

4. vote /v/

5. suffer $/ \mathbf{f} /$

6. sigh /s/

7. sign $/ \mathbf{s} /$

8. pan /p/

9. bent /b/

10. wrong $/ \mathbf{r} /$

11. fry $/ \mathbf{r} /$

12. fill /f/

13. vow /v/

14. lace ///

15. shame / $/$

16. alive /// 


\section{APPENDIX C}

Instruction: Read each pair of words. Record them when you read.

1. depend- defend

2. ban-van

3. rain-lane

4. fine-pine

5. she-sea

6. rock-lock

7. fool-pool

8. mash-mass

9. Gabe-gave

10. prank- frank

11. sip-ship

12. bolt-volt

13. rip-lip

14. sore-shore

15. pray-play

16. curb-curve 


\section{APPENDIX D}

Instruction: look at the picture. Please describe the picture in as much detail as you can.

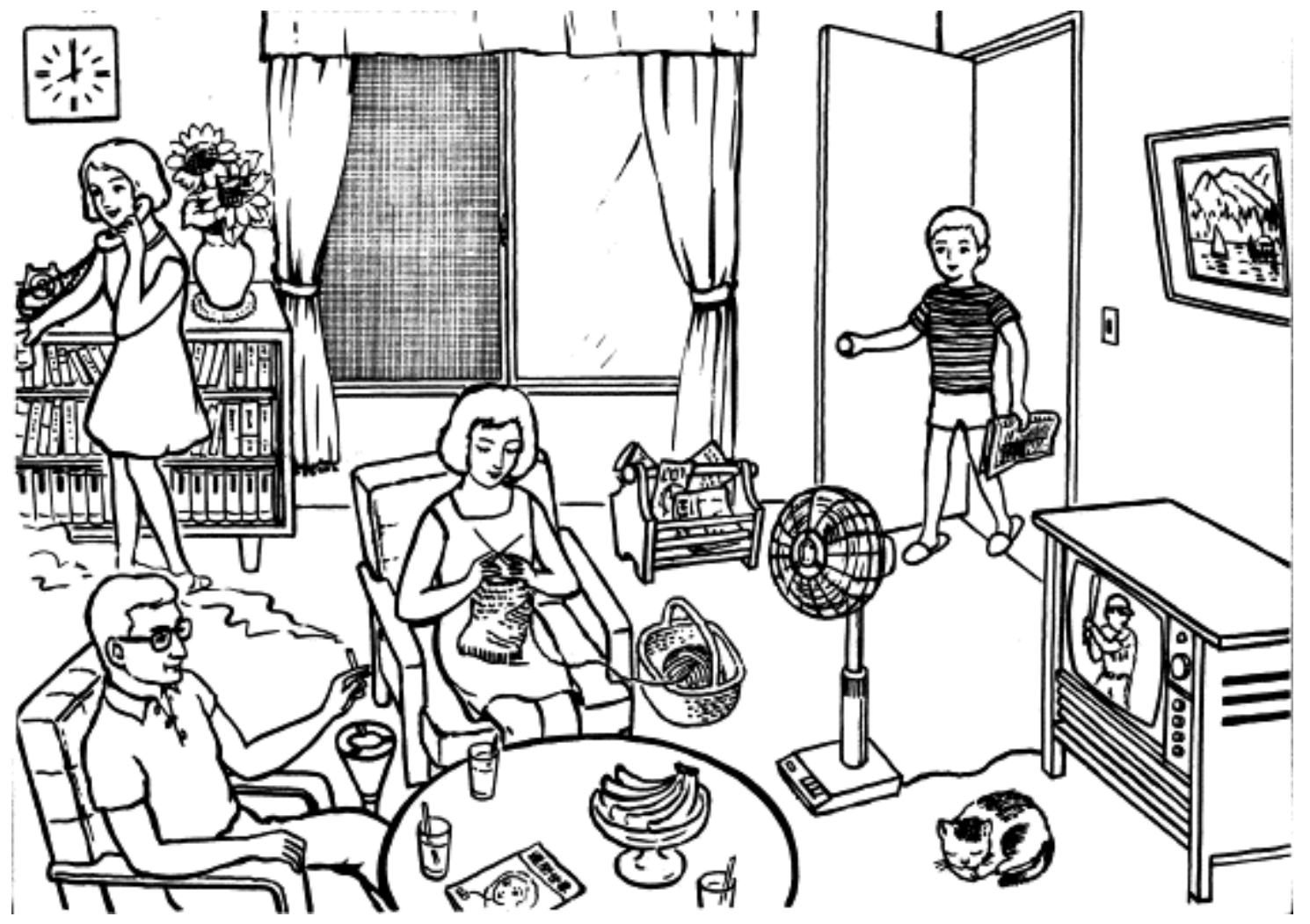

Source: Shimada, M., Meguro, K., Yamazaki, H., Horikawa, A., Hayasaka, C., Yamaguchi, S., Yamadori, A. (1998). Impaired verbal description ability assessed by the picture description task in alzheimer's disease. Archives of Gerontology and Geriatrics, 27(1), 57-65. 


\section{APPENDIX D}

\section{Picture Description}

Teacher's guideline: students will look at the picture and they will describe in as much detail as they can. When there are not enough descriptions, the teacher will provide a few questions to lead students to elicit some particular sounds.

[Possible Questions]

1. Who is in the picture?

2. What are they doing?

3. What is in the picture?

4. What is he doing? (while pointing at the male grown up)

5 . What is the young boy wearing?

6. What is next to the cat?

7. What is the painting in the wall about?

8. What is on the table?

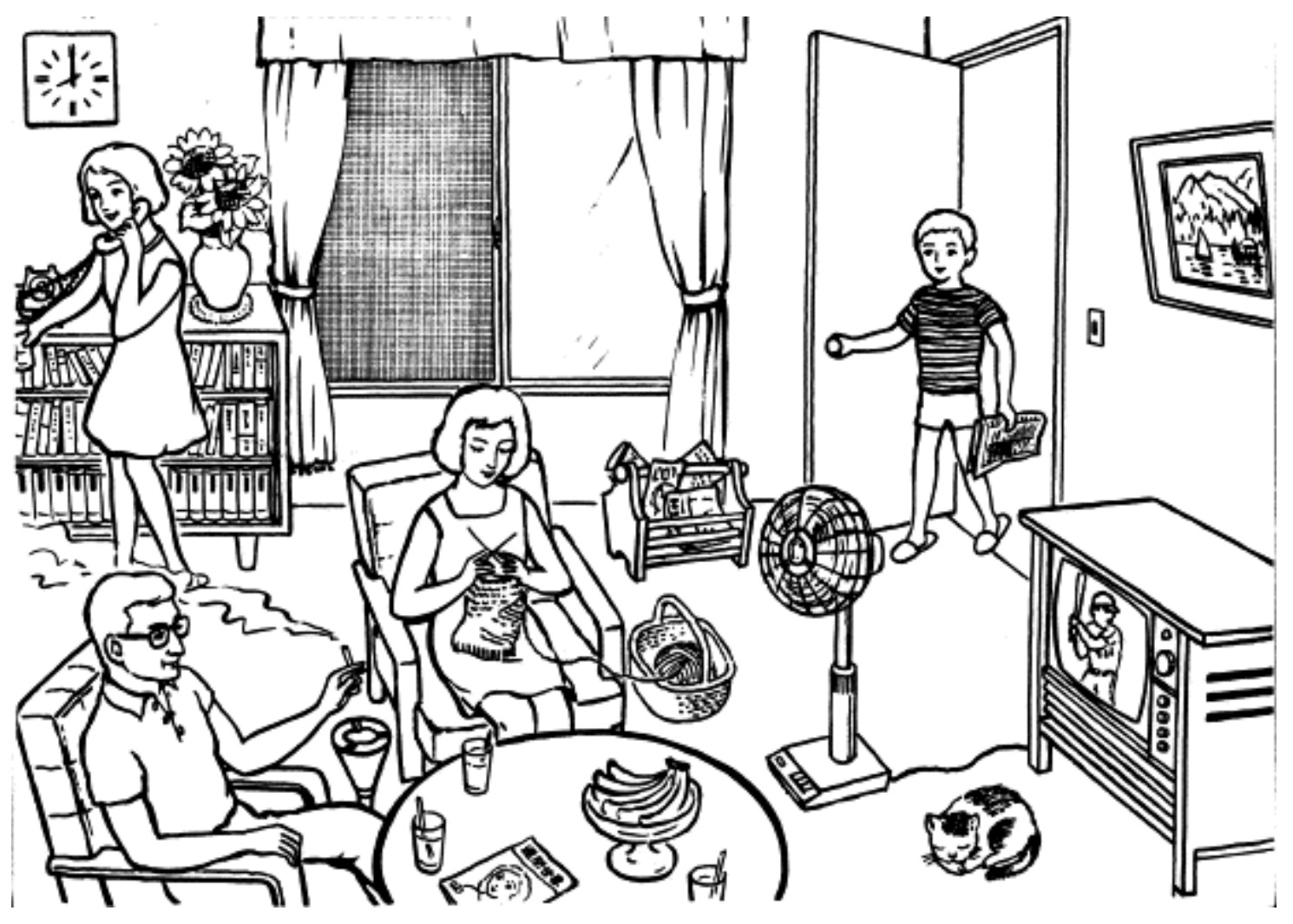

Source: Shimada, M., Meguro, K., Yamazaki, H., Horikawa, A., Hayasaka, C., Yamaguchi, S., Yamadori, A. (1998). Impaired verbal description ability assessed by the picture description task in alzheimer's disease. Archives of Gerontology and Geriatrics, 27(1), 57-65. 


\section{APPENDIX E}

\section{Class: Korean ESL Learners Phonetic Class}

\section{Instructor: Moonjung Jang}

Date:

Day: Day 1

Lesson Plan

Previous classwork: Pre-test on minimal pairs, /b/-/v/, /p/-/f/, /s/-/ /, and /r/-/1/.

Objectives: To acquire the concept of place of articulation, manner of articulation, And voicing.

SWBATS: To identify where each sound comes from in terms of place of articulation, manner of articulation, and voicing.

Materials: Lesson plan, roster, excerpt from Avery, P., \& Ehrlich, S. (2000). Teaching American English pronunciation (Oxford handbooks for language teachers), PowerPoint, index cards,

What is upcoming: Day 2: Minimal pairs, /b/-/v/, /p/-/f/, /s/-/s/, and /r/-/l/.

Procedure

\begin{tabular}{|c|c|c|}
\hline Time & Procedures & Considerations \\
\hline $8: 58-9: 00$ & $\begin{array}{l}\text { Warm up: } \\
\text { Roster } \\
\text { Greeting }\end{array}$ & \\
\hline 9:00-9:10 & $\begin{array}{l}\text { Place of articulation: } \\
\text { The teacher will explain the } \\
\text { concept of place of } \\
\text { articulation and introduce } \\
\text { different places of } \\
\text { articulation with pictures. }\end{array}$ & \\
\hline $9: 10-9: 20$ & $\begin{array}{l}\text { Manner of articulation: } \\
\text { The teacher will explain the } \\
\text { concept of manner of } \\
\text { articulation and introduce } \\
\text { different manners of } \\
\text { articulation with pictures. }\end{array}$ & \\
\hline $9: 20-9: 30$ & $\begin{array}{l}\text { Voicing: } \\
\text { The teacher will explain the } \\
\text { concept of voicing and } \\
\text { introduce voicing with } \\
\text { tables. }\end{array}$ & $\begin{array}{l}\text { Preparation: } \\
\text { To maximize the impact of } \\
\text { visual aid, the teacher will } \\
\text { distribute index cards to } \\
\text { students. Students will place }\end{array}$ \\
\hline
\end{tabular}




\begin{tabular}{|c|c|c|}
\hline & & $\begin{array}{l}\text { the index cards in front of } \\
\text { their mouths when they } \\
\text { produce voiced and } \\
\text { voiceless sounds. }\end{array}$ \\
\hline $9: 30-9: 40$ & $\begin{array}{l}\text { /b/-/v/: } \\
\text { Students will learn where } \\
\text { and how } / \mathrm{b} / \text { and } / \mathrm{v} / \text { sound } \\
\text { come from the mouth. They } \\
\text { will compare the differences } \\
\text { between } / \mathrm{b} / \text { and } / \mathrm{v} / \text { in terms } \\
\text { of place of articulation, } \\
\text { manner of articulation, and } \\
\text { voicing. }\end{array}$ & $\begin{array}{l}\text { Preparation: } \\
\text { The teacher will show the } \\
\text { pictures of place of } \\
\text { articulation and manner of } \\
\text { articulation. }\end{array}$ \\
\hline $9: 40-9: 50$ & $\begin{array}{l}\text { /p/-/f/: } \\
\text { Students will learn where } \\
\text { and how } / \mathrm{p} / \text { and } / \mathrm{f} / \text { sound } \\
\text { come from the mouth. They } \\
\text { will compare the differences } \\
\text { between } / \mathrm{p} / \text { and } / \mathrm{f} / \text { in terms } \\
\text { of place of articulation, } \\
\text { manner of articulation, and } \\
\text { voicing. }\end{array}$ & $\begin{array}{l}\text { Preparation: } \\
\text { The teacher will show the } \\
\text { pictures of place of } \\
\text { articulation and manner of } \\
\text { articulation. }\end{array}$ \\
\hline $9: 50-9: 58$ & $\begin{array}{l}\text { Practice: } \\
\text { Students will practice } \\
\text { minimal pairs of } / \mathrm{b} /-\mathrm{v} / \text { and / } \\
\text { p/-/f/. }\end{array}$ & \\
\hline $9: 58-10: 00$ & $\begin{array}{l}\text { Q\&A: } \\
\text { Students will ask questions } \\
\text { if they have any. }\end{array}$ & \\
\hline
\end{tabular}

\section{Attendance ( )}




\section{APPENDIX E}

\section{Class: Korean ESL Learner Phonetic Class}

\section{Instructor: Moonjung Jang}

Date:

Day: Day 2

Lesson Plan

Previous classwork: Lecture on place of articulation, manner of articulation, and voicing.

Objectives: To distinguish the differences between the minimal pairs, /b/-/v/, /p/-/f/, $/ \mathrm{s} /-/ \mathrm{s} /$, and $/ \mathrm{r} /-/ 1 /$.

SWBATS: To produce clear distinctions between the minimal pairs, /b/-/v/, /p/-/f/, /s/-/s/, and /r/-/1/.

Materials: Lesson plan, roster, excerpt from Avery, P., \& Ehrlich, S.

(2000). Teaching American English pronunciation (Oxford handbooks for language teachers), PowerPoint.

What is upcoming: Post-test on the minimal pairs, /b/-/v/, /p/-/f/, /s/-/ /, and /r/-/l/ a week after the day 2 class.

\section{Procedure}

\begin{tabular}{|c|c|c|}
\hline Time & Procedures & Considerations \\
\hline $8: 58-9: 00$ & $\begin{array}{l}\text { Warm up: } \\
\text { Roster } \\
\text { Greeting }\end{array}$ & \\
\hline $9: 00-9: 10$ & $\begin{array}{l}\text { Review: } \\
\text { Students will review place } \\
\text { of articulation, manner of } \\
\text { articulation, and voicing. }\end{array}$ & $\begin{array}{l}\text { Preparation: } \\
\text { The teacher will show the } \\
\text { pictures of place of } \\
\text { articulation and manner of } \\
\text { articulation. }\end{array}$ \\
\hline $9: 10-9: 20$ & $\begin{array}{l}\text { /s/-/ } / \text { : } \\
\text { Students will learn where } \\
\text { and how } / \mathrm{s} / \text { and } / \int / \text { sound } \\
\text { come from the mouth. They } \\
\text { will compare the differences } \\
\text { between } / \mathrm{s} / \text { and } / \int / \text { in terms } \\
\text { of place of articulation, } \\
\text { manner of articulation, and } \\
\text { voicing. }\end{array}$ & $\begin{array}{l}\text { Preparation: } \\
\text { The teacher will show the } \\
\text { pictures of place of } \\
\text { articulation and manner of } \\
\text { articulation. }\end{array}$ \\
\hline
\end{tabular}




\begin{tabular}{|c|c|c|}
\hline $9: 20-9: 30$ & $\begin{array}{l}/ \mathbf{r} /-/ \mathbf{l} / \\
\text { Students will learn where } \\
\text { and how } / \mathrm{r} / \text { and } / 1 / \text { sound } \\
\text { come from the mouth. They } \\
\text { will compare the differences } \\
\text { between } / \mathrm{r} / \text { and } / 1 / \text { in terms } \\
\text { of place of articulation, } \\
\text { manner of articulation, and } \\
\text { voicing. }\end{array}$ & $\begin{array}{l}\text { Preparation: } \\
\text { The teacher will show the } \\
\text { pictures of place of } \\
\text { articulation and manner of } \\
\text { articulation. }\end{array}$ \\
\hline 9:30-9:40 & $\begin{array}{l}\text { Practice: } \\
\text { Students will practice } \\
\text { minimal pairs of } / \mathrm{s} /-/ \int / \\
\text { and } / \mathrm{r} /-/ 1 / \text {. }\end{array}$ & \\
\hline $9: 40-9: 50$ & $\begin{array}{l}\text { Final Practice: } \\
\text { Students will practice } \\
\text { minimal pairs of } / \mathrm{b} /-/ \mathrm{v} / \text { and / } \\
\text { p/-/f/. }\end{array}$ & \\
\hline $9: 50-9: 58$ & $\begin{array}{l}\text { Final Practice: } \\
\text { Students will practice } \\
\text { minimal pairs of } / \mathrm{s} /-/ \mathrm{J} / \\
\text { and } / \mathrm{r} /-/ 1 / \text {. }\end{array}$ & \\
\hline $9: 58-10: 00$ & $\begin{array}{l}\text { Q\&A: } \\
\text { Students will ask questions } \\
\text { if they have any. }\end{array}$ & \\
\hline
\end{tabular}

\section{Attendance ( ):}




\section{APPENDIX F}

Day 1 Activity

Name

1. Instruction: You will listen to the recording. Circle the sound you have heard.

1. fashion - passion

2. found - pound

3. vest - best

4. Viking - biking

5. beer - veer

6. Serb - serve

7. bale - veil

8. foot - put

9. fax - packs

10. fig- pig

2. Instruction: Working in pairs each partner will receive a different list of words. Each pair will practice the lists. Each pair will produce their lists, listen to each other, and help each other to produce the right pronunciation. The teacher will walk around to provide feedback.

[Student A]

\begin{tabular}{|l|l|}
\hline lubber & rove \\
\hline valance & bend \\
\hline liber & flop \\
\hline pair & pail \\
\hline chief & beef \\
\hline
\end{tabular}

[Student B]

\begin{tabular}{|l|l|}
\hline lover & robe \\
\hline vend & balance \\
\hline liver & fair \\
\hline cheap & fail \\
\hline beep & plop \\
\hline
\end{tabular}

3. Instruction: You will use the "voice-controlled personal digital assistant" of your smartphone. You will read the list of the words to find pictures of the words. For 
example, you will say "show me a picture of a foot." Try the list and mark how many words you have gotten right.

1. robe

2. balance

3. liver

4. pail

5. chief

6. beef

7. vest

8. beer

9. pig

10.veil 


\section{APPENDIX F}

Day 2 Activity Name

1. Instruction: You will listen to the recording. Circle the sound you have heard.

1. sock- shock

2. load-road

3. locker-rocker

4. law-raw

5. save- shave

6. sort- short

7. clown- crown

8. sell- shell

9. flee- free

10. sign-shine

2. Instruction: Working in pairs each partner will receive a different list of words. Each pair will practice the lists. Each pair will produce their lists, listen to each other, and help each other to produce the right pronunciation. The teacher will walk around to provide feedback.

[Student A]

\begin{tabular}{|l|l|}
\hline lack & chic \\
\hline seat & shaggy \\
\hline liver & wrist \\
\hline sew & rate \\
\hline sack & low \\
\hline
\end{tabular}

[Student B]

\begin{tabular}{|l|l|}
\hline rack & seek \\
\hline sheet & river \\
\hline saggy & list \\
\hline show & late \\
\hline shack & row \\
\hline
\end{tabular}

3. Instruction: You will use the "voice-controlled personal digital assistant" of your smartphone. You will read the list of the words to find pictures of the words. For 
example, you will say "show me a picture of a foot." Try the list and mark how many words you have gotten right.

1. sock

2. road

3. rocker

4. clown

5. shell

6. sign

7. seat

8. river

9. wrist

10. law

4. Instruction: look at the pictures and answer the questions.

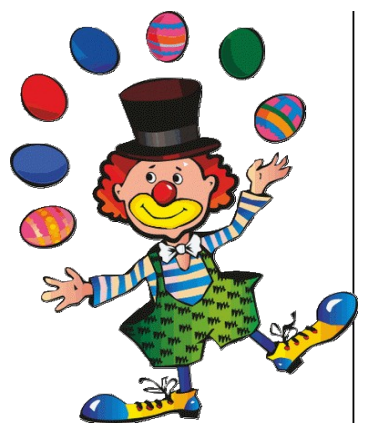

1. What is the name of the person?

2. Look at his foot. Do you think he has a big foot or a small foot?

3. Can you describe his face? Such as "his nose is red."

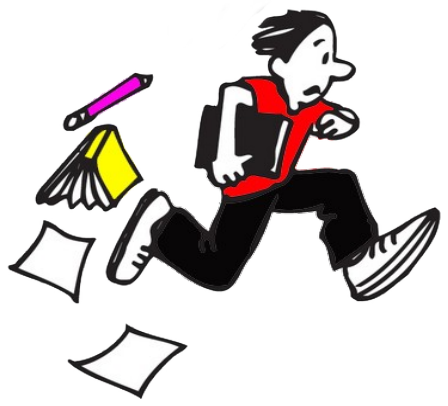

1. It seems like he's busy. Do you think he's early or late for the class?

2. Do you think he is walking or running?

3. Describe his outfits. 
1. Do you know what to call this type of outfit?

2. What color is this?

3. What is your favorite fashion style? 